\title{
Public Procurement with Unverifiable Quality: The Case for Discriminatory Competitive Procedures*
}

\author{
Gian Luigi Albano ${ }^{\dagger} \quad$ Berardino Cesi ${ }^{\ddagger} \quad$ Alberto Iozzi $^{\S}$
}

October 24, 2016

\begin{abstract}
Unverifiable quality may affect the enforcement of procurement contracts even when the award procedure is able to select the most efficient firm in the market. In this paper, we show that a discriminatory competitive mechanism - which awards the contract on the basis of price and (firms') past performance - yields an efficient allocation of the contract and allows the buyer to implement her desired quality. Quality enforcement arises out of relational contracting whereby the buyer 'handicaps' a contractor in future competitive tendering processes if it fails to provide the required quality. We study an infinitely repeated procurement model with two firms and one buyer imperfectly informed on the firms' cost, in which, in each period, the buyer runs a discriminatory auction. We restrict our analysis to the case of a buyer committed to her handicapping strategy, a case which captures some of the features of a public buyer. When players use either grim trigger or stick-and-carrot strategies, we find that the buyer can induce the delivery of optimal (unverifiable) quality with a variety of handicap levels and, when applicable, durations of the punishment period; for some values of the handicap and the length of the punishment period, both firms remain active in the market even when punished.
\end{abstract}

Keywords: public procurement, relational contracts, unverifiable quality, handicap.

\footnotetext{
${ }^{*}$ We are grateful to Roberto Burguet, Giacomo Calzolari, Daniel Danau, Nicola Doni, Elisabetta Iossa, Bruno Jullien, Stefano Lovo, Mario Pagliero, Francesco Sobbrio, Giancarlo Spagnolo, Marco Sparro, Tommaso Valletti, Annalisa Vinella, Michael Waterson and seminar participants at Corfu (CRESSE), Leicester, Milano Bocconi (EARIE), Pavia (SIEP), Pescara, Taormina (EDSI), Torino (NERI) and Roma 'Tor Vergata' for useful comments. We also wish to thank the editor and three referees of this journal, whose comments led to a substantial improvement of this paper.

${ }^{\dagger}$ Consip S.p.A. (The National Central Purchasing Body, Italy) and LUISS Guido Carli: gianluigi.albano@consip.it.

‡Università di Roma 'Tor Vergata': berardino.cesi@uniroma2.it.

§Università di Roma 'Tor Vergata' and SOAS, University of London: alberto.iozzi@uniroma2.it.
} 


\section{Introduction}

Open competition in procurement processes is, in many circumstances, the most appropriate procedure to ensure the selection of the most efficient contractor. This is true when the quality of the procured object is endogenous and is verifiable by a third party at a reasonable cost, since fines can be specified so as to deter the contractor from breaching contract clauses, and from reneging on promised quality levels. ${ }^{1}$ There exist cases, though, in which procurement contracts are characterised by quality dimensions that are observable by contracting parties but that are hard, if not impossible, to verify. Examples would include IT or management consulting services, where the quality of human capital is a multidimensional variable comprising unverifiable dimensions, such as a consultant's proactiveness or ability to provide innovative solutions. Lack of verifiability may also affect quality dimensions such as user-friendliness of a software or food palatability in catering services.

The relevant literature has, thus far, explored two potential solutions to quality non-verifiability in competitive procedures. The first approach shows that a buyer should avoid using a competitive procedure to award a procurement contract (Manelli and Vincent, 1995); rather, she should rely on negotiation-like procedures with a restricted set of highly reputable suppliers. ${ }^{2}$ Overall, this approach emphasises that, when quality is not verifiable, there seems to exist a trade-off between the objectives of efficiency and quality provision: although well-performing in terms of efficiency (i.e., the ability to procure from the most efficient supplier at the lowest price), competitive procedures are not able to ensure quality. The latter is best obtained by means of negotiation-like procedures, which, however may not perform well in terms of efficiency. The second approach (Klein and Leffler, 1982; Board, 2011; Calzolari and Spagnolo, 2013; and Auriol and Søreide, 2015) still relies on the use of competitive procedures, but endows the buyer with an extremely harsh punishment device when quality is not delivered - she can debar the cheating firm from the competitive environment. In other words, a cheating firm faces the potential threat of being unable to submit a bid for the relevant contract in the future.

The paper's main objective is to prove that there exists a third mechanism that allows the buyer to elicit soft quality provision in procurement markets. This mechanism takes the form of a discriminatory scoring auction in which the scoring rule evaluates a firm's bid and 'handicap' based on the firm's performance in executing the same task in the past. ${ }^{3}$ When repeated over time, the interaction between the buyer and the contractor turns out to be an instance of a 'relational procurement contract' (RPC, henceforth), which allows the buyer to select the most efficient

\footnotetext{
${ }^{1}$ This conclusion would hold under the assumptions of effective contract management and law enforcement.

${ }^{2}$ For an empirical analysis, see Bajari et al. (2009), Estache et al. (2009), and Lalive and Schmutzler (2011).

${ }^{3}$ Discrimination may also take the form of a positive reward, although it may not necessarily depend on firms' past performance. For instance, discriminatory mechanisms are applied in favour of small or domestic firms in the US. Favouritism may be also tuned to the suppliers' efficiency (see Naegelen and Mougeot, 1998; Branco, 2002; and Vagstad, 1995). Another form of favouritism is the one of 'set-asides' for small and medium-sized firms provided for by the U.S. Federal Acquisition Regulation and by procurement regulation in South Africa and China. Positive discrimination may also take the form of 'bidding credits', like the ones used for the regional radio spectrum auctions in the U.S. in 1993. Ayres and Crampton (1996) show that allowing bidding credits to firms owned by women and minorities increased both competition among auction participants and the government's revenue.
} 
supplier and to obtain the required quality level by using the threat of putting the contractor at a disadvantage in future tenders, thus reducing its (expected) stream of future profits. ${ }^{4}$ Since the handicap may be smoothly fine-tuned, a reputation-enhanced auction is a much more flexible and politically viable instrument than the draconian punishment of excluding a 'cheating' firm from the bidding market altogether. Also, since it encompasses the case of exclusion of the 'cheating' firm, our model of discriminatory scoring auction allows us to study under what conditions either form of punishment turns out to be optimal for the buyer. ${ }^{5}$ Indeed, although we do not explicitly deal with this issue in the paper, formal exclusion might become detrimental to the level of competition in future tendering processes if entry in the procurement market is limited. This is often the case when procurement contracts require specialised know-how and/or sizeable fixed costs for drafting proposals for designing, say, complex ICT systems or infrastructures.

The competitive mechanism studied in this paper is consistent with the solutions adopted in some international regulations. In particular, it mimicks the main characteristics of past performance evaluation in the U.S. federal regulation on public procurement. ${ }^{6}$ Indeed the U.S. Federal Acquisition Regulation (FAR) prescribes that "[p]ast performance should be an important element of every evaluation and contract award for commercial items" (U.S. General Services Administration, 2016, part 12.206). The FAR also provides (federal) agencies with broad discretion in deciding how they will consider firms' prior experience - whether the firms have done similar work before - and past performance - how well they have done that work. In this respect, a 2011 report by the U.S. Government Accountability Office (GAO) on the use of past performance in awarding federal contracts emphasises that "in almost all procurements [...] the contracts were awarded to the offerors that received the highest rating for nonprice factors, such as prior experience or past performance" (U.S. Government Accountability Office, 2011, p. 2).

To prove our results, we build a dynamic game, resulting from an infinite repetition of a sequential game with three players: one buyer and two competing firms. ${ }^{7}$ The buyer competitively awards a contract for a project whose quality is ex-post observable by trading parties, but not verifiable. When running the auction, the buyer is uninformed about the firms' (fixed) cost,

\footnotetext{
${ }^{4}$ Long-term relationships are also more likely to emerge in those procurement markets populated by a stable set of few firms rather than in ones in which firms' turnover is high. Some procurement markets in which the issue of unverifiable quality is more prominent, such as those for highly specialised consulting services (i.e., strategy consulting or ICT consulting), seem to be characterised by this feature.

${ }^{5}$ To be sure, in our model a harsh handicap does not imply a formal exclusion of the punished firm from the procurement market, but it results in a de facto debarment: the firm remains active although is put at such a competitive disadvantage that it cannot outbid its rival and thus be awarded a contract. For ease of exposition, in the remainder of the paper, we shall use 'debarment' only.

${ }^{6}$ In the EU, instead, discriminatory evaluation criteria may conflict with articles 3 and 87 of the EC Treaty; see Maasland et al. (2004). Past performance can only be used to exclude a firm from competing for a public contract. According to article 57.4 of the EU Directive 2014/24/EU: "Contracting authorities may exclude or may be required by Member States to exclude from participation in a procurement procedure any economic operator in any of the following situations: [...] (g) where the economic operator has shown significant or persistent deficiencies in the performance of a substantive requirement under a prior public contract, a prior contract with a contracting entity or a prior concession contract which led to early termination of that prior contract, damages or other comparable sanctions". This means that past performance might be taken into account only as a 'selection criterion', that is, whether or not a firm can submit a tender for a public contract.

${ }^{7}$ The buyer is referred to as she, while both firms are referred to as $i t$.
} 
whereas each firm is fully informed of the rival's cost. The competitive process is (possibly) discriminatory, in the sense that the buyer awards the project on the basis of the firms' bids and of the handicap placed on the firm(s) which delivered a lower-than-desired level of quality in the past.

We assume the buyer to be able to commit to her strategy, in the sense that she is not able to deviate from her past performance evaluation strategy along the play of the game. The case of commitment captures some of the features of a public buyer - say, a central government body carrying out procurement processes according to an exogenously given regulation which may constrain the buyer's ability to change her evaluation scheme. The FAR provides quite some evidence of the constraints 'tying the hands' of a federal buyer when the latter adopts a past performance evaluation system. For instance, subpart 42.15 (Contract Performance Information) of the FAR is aimed mainly at standardising the criteria to be used by federal agencies in evaluating contractors' past performance (U.S. General Services Administration, 2016). Moreover, past performance evaluation criteria need to be clearly stated before tenders are submitted, especially when they carry a high weight in the overall weighting system. ${ }^{8}$ This becomes compelling when past performance evaluation results in suspension/debarment. Borrowing the words of a 2008 Congressional report: “[...] debarments are often mandatory, leaving no discretion to contracting officers; are punishments; and last for a period prescribed by statute, with limited opportunities for agencies to waive them" (Congressional Research Service, 2008, p. 21). To strengthen such a commitment power, the decision of suspension/debarment is typically taken by another organisational unit that was not involved in the tenders evaluation procedure. ${ }^{9}$

We study two versions of the repeated game, one in which players use grim trigger and the other in which they use stick-and-carrot strategies. While grim trigger strategies, although difficult to map to reality, are able to clearly pin down the trade-offs between short-run benefits and long-run costs of a deviation, stick-and-carrot strategies seem more attractive in the analysis of public procurement, as a public buyer may be unable to use an infinitely long punishment. Stick-and-carrot strategies are well-suited to capture the features of time-limited punishments for poor past performance. Evidence about both the exact duration of handicapping schemes and the exact (time-related) definition of past performance is scant. However, precise information is available concerning the time-limited nature of harsher forms of punishment, namely suspension and debarment. Indeed, subpart 9.4 of the FAR establishes accurate policies and procedures governing suspension and debarment actions related to federal contracts (U.S. General Services Administration, 2016). A suspension is a temporary exclusion pending the completion of an investigation or legal proceeding which generally may not last longer than 18 months, while a

\footnotetext{
${ }^{8} \mathrm{~A}$ quite enlightening case is provided by a request for proposals (RFP) issued to procure meals, lodging, and transportation for newly arrived U.S. Army soldiers. Dietz (2002) emphasises that "[t]he RFP was silent on the role of any non-price evaluation factor other than past performance. Past performance was set forth in considerable detail, including how it would be used and what would be considered" (p. 36).

${ }^{9}$ For instance, according to a 2014 GAO Report, the Department of Veteran Affairs has a Debarment and Suspension Committee with a staff of about 10 positions that review all referrals for procurement-related suspension and debarment actions, conduct fact-finding, and present facts and recommendations to the Suspension and Debarring Official (U.S. Government Accountability Office, 2014, p. 13).
} 
debarment is an exclusion for a reasonable, specified period depending on the seriousness of the cause, but generally should not exceed 3 years. ${ }^{10}$ Both provisions then limit the time during which a firm is forbidden to be awarded a public contract, a feature which is in the spirit of stick-and-carrot strategies.

Equilibria have similar features under the different hypotheses on the players' strategies. Under both grim trigger and stick-and-carrot strategies, when players are sufficiently patient, we find that a self-enforcing pair of RPCs is able to select the efficient supplier and induce it to deliver the optimal quality level. This holds provided that the handicap the buyer imposes on any firm which delivered a suboptimal quality level in the past is higher than the contractor's cost savings when it fails to deliver quality. Since the handicap is never imposed along the equilibrium path but only acts as a threat in case of a deviation, the buyer is able to obtain quality without leaving the contractor with any profits in excess of what it would make in a static competitive procedure when quality is verifiable. Different levels of the handicap are possible in equilibrium, thus providing the buyer with quite some room of manoeuvre: with a low handicap, a deviating firm remains active in the market; when, instead, the handicap is high enough, a deviating firm is put at such a competitive disadvantage that it cannot outbid its rival. This case gives rise to a de facto debarment, in that the handicapped firm is not formally excluded from the procurement market, but no longer has a chance to be awarded a contract.

When grim trigger strategies are in use, and the handicap is sufficiently low that no debarment occurs in case of a deviation, we find an inverse relationship between the handicap and the lowest discount factor ensuring cooperation. If, instead, the handicap is sufficiently high that debarment occurs after a deviation, the critical discount factor does not depend on the handicap level since the punishment is harsh enough. A similar result is found in the case of players using stick-and-carrot strategies; when the handicap is sufficiently low and no debarment occurs in case of a deviation, an inverse relationship between the handicap and the minimal punishment length arises. When the handicap is high enough so that debarment occurs, this inverse relationship disappears.

The paper is organised as follows. After reviewing the related literature in Section 2, we describe the model in Section 3. Section 4 analyses the dynamic game, under the different assumptions on the players' strategies. Section 5 concludes. All proofs are relegated to the Appendix.

\section{Related Literature}

Our paper contributes to the large literature studying the enforcement of unverifiable quality in procurement, first analysed by Lewis and Sappington (1991), Laffont and Tirole (1993) and Che (1993). While these papers and the ensuing literature look at this issue in the static setup of incentive and auction theory, ${ }^{11}$ we set up our analysis in the context of a repeated interaction

\footnotetext{
${ }^{10}$ To be sure, both suspension and debarment are also provided for by other public procurement regulations, most notably the EU procurement regulation (see Directive 2014/24/EU, article 57). In this case too, these punishments are time-limited.

${ }^{11}$ See, for instance, Hanazono et al. (2013) and Giebe and Schweinzer (2015).
} 
between our players, thus investigating relational contracts and the incentives that they create to provide quality. Relational contracts are informal agreements and unwritten codes of conduct that are sustained by the value of future relationships, and are applicable in cases where the outcome of a repeated relationship is based on some unverifiable variables. ${ }^{12}$

Several papers have conducted the analysis of opportunistic behaviour in repeated procurement in the context of a long-term relationship. Klein and Leffler (1981) show that an optimal strategy for the buyer is to promise a rent to the contractor under the threat of terminating the relationship in case of opportunistic behaviour. Dalen et al. (2006) study a model in which a third party provides a quality ranking subject to noise; they show that when the reward for the supplier is given by a certain probability of the contractual renewal, then the incentive to induce quality is maximal if $50 \%$ of the contracts are renewed. Kim (1998) shows that restricting the number of admitted participants in a competitive procedure may induce the competitors to provide a high quality. Doni (2006) introduces unverifiable quality in the competitive multidimensional pricequality auction of Asker and Cantillon (2008); he shows that a buyer may use a reputational mechanism based on an index of past performance to induce the contractor to deliver a required level of unverifiable quality.

A paper closely related to ours is Calzolari and Spagnolo (2013, CS henceforth). This and our paper share a similar set-up of a repeated game with one buyer and many privately-informed agents delivering a non-contractible project. In a model which allows an unspecified number of firms in the market and the possibility of transfers and bonuses, CS show that a firm has the incentive to deliver quality if the buyer has the power to exclude it from future competitive tendering procedures in case it fails to deliver quality. When the value of quality or the number of potential bidders is low, the threat of preventing a firm to participate to future open competitive procedures after a deviation is sufficient to ensure the provision of quality. When, instead, the value of quality or the number of potential bidders is high, the buyer finds it optimal to restrict the number of firms from the beginning to increase the (expected) payoff of firms when delivering quality. The main difference with our paper is that CS take exclusion as the only possible punishment, whereas we endow the buyer with a continuum of punishment levels to the deviating firm, which remains active in the market even after a deviation. This difference in the buyer's strategy spaces makes the nature of competition after a firm's deviation different across the two papers: in CS, after a deviation, the 'surviving' firms remain (ex-ante) symmetric, whereas in our case the use of a handicap generates asymmetries, even from an ex-ante perspective, between the competing firms. The different nature of competition is reflected in different firms' bids and on- and off-equilibrium payoffs. In CS, a firm's 'cooperative' expected payoff is a decreasing function of the number of active firms; in our case, it does not depend on the number of active firms (which is always constant) but depends on the rival's handicap (if any). Off the equilibrium path, the expected

\footnotetext{
${ }^{12}$ Relational contracts have been pioneered by Bull (1987) and MacLeod and Malcomson (1989) and applied in several fields: labour market (MacLeod, 2003; Levin, 2003; and Li and Matouschek, 2013), interaction between/within firms (Baker et al., 2002; and Rayo, 2007), regulation (Cesi et al., 2012) and experimental economics (Fehr and Schmidt, 2007; and Bigoni et al., 2014).
} 
payoff after a deviation is always zero in CS, whereas in our paper it is decreasing in the firm's handicap and possibly positive. These differences generate different incentives for the players to stick to the relational procurement contract; thus, across the two papers, while the players' strategies on the equilibrium path are similar, the characterisations of the equilibria are different. Furthermore, CS analyse both cases of a committed and an uncommitted buyer (whereas we look at the case of committed buyer only) and we analyse both cases of infinite and time-limited punishments (whereas an exclusion is always everlasting in CS).

Board (2011) also studies how restricting the number of agents may help enforce the provision of unverifiable tasks; he studies a model between a buyer and many suppliers, in which the buyer may make a costly investment in one of the suppliers, while the supplier can hold up the buyer by ex-post appropriating the outcome of the relationship. He characterises the optimal relational contract, which solves the hold-up problem and shows that the buyer may have an incentive to deal on different terms between insiders (those firms that the buyer has already traded with) and outsiders. ${ }^{13}$

Che (2008) provides and reviews solutions to the problem of unverifiable quality, other than in the context of relational contracts. Among others, Taylor (1993) and Che and Hausch (1999) introduce an option contract whereby the supplier pays a fee to the buyer, who then may accept or reject (at no penalty) the provision at a price equal to its desired level of quality. Che and Gale (2003) show that a buyer may be better off by allowing suppliers to bid on their reward, as in a standard auction. Other papers, in line with Manelli and Vincent (1995), study the enforcing power of competitive procedures versus negotiations when quality is unverifiable; Tunca and Zenios (2006), among the others, study the interaction between a competitive auction and a relational contract. Buyers procure low-quality products by running a competitive price auction and high-quality products by means of a relational contract with a single supplier. They find that, for some values of quality, the use of competitive auctions for low-quality products may ease the enforcement of relational contracts for high-quality products. ${ }^{14}$

Our paper is also connected to the literature on scoring auctions in procurement. A number of papers study the enforcing role of a scoring multidimensional auction when quality is verifiable, again comparing a scoring auction with a negotiation-like procedure. ${ }^{15}$ For instance, Asker and Cantillon $(2008,2010)$ show that scoring auctions perform better than price-only auctions or negotiation and may induce a performance similar to that of the optimal mechanism. In our approach, the unverifiable nature of quality makes it unfeasible to envisage the possibility of firms also bidding on quality, thus reducing the role of the scoring rule.

\footnotetext{
${ }^{13}$ Boudreau et al. (2001) have empirically studied the role of the number of competitors in procurement.

${ }^{14}$ See, also, Branco (1997), Wang (2000), Kessler and Lülfesmann (2004) and Milgrom (2004). Empirical analyses provide mixed evidence. Bajari et al. (2009), studying the private-sector building contracts in Northern California from 1995 to 2000, find that those awarded by negotiation perform better. On the other hand, analysing the procurement of regional railway services in Germany, Lalive and Schmutzler (2011) find that auctioned lines provide a higher frequency of service (seen as a proxy for quality) compared to lines awarded by direct negotiations. ${ }^{15}$ See the references cited in footnote 20.
} 


\section{The model}

The players. A public buyer wishes to procure a single project of variable quality $q$. This procurement activity takes place at time $t$ and it is repeated for an infinite number of periods, so that $t=0, \ldots, \infty$. Two firms, 1 and 2 , can compete for the project. At each $t$, a firm's cost is $c\left(\theta_{i t}, q_{i t}\right)=\theta_{i t}+\psi\left(q_{i t}\right)$, where $i=1,2$ and $t=0, \ldots, \infty$ (we will drop the time subscript whenever possible); that is, the total cost for carrying out the contract consists of a fixed firm-specific component, $\theta_{i}$, and of a quality-dependent component, $\psi\left(q_{i}\right)$, identical across firms. ${ }^{16}$

We assume that the fixed cost parameter for each firm is a random variable with only two possible realisations, $\theta_{L}$ and $\theta_{H}$, with $\theta_{L}<\theta_{H}$. We denote with $\Delta \theta \equiv \theta_{H}-\theta_{L}$ the largest cost advantage that one of the two firms may have on the fixed cost component. Both firms face an identical and time-invariant probability of realisation of $\theta_{L}$, which we denote with $\beta$, where $\beta \in[0,1]$. Hence, for $i=1,2$ and $t=0, \ldots, \infty, \operatorname{Pr}\left(\theta_{i t}=\theta_{L}\right)=\beta$.

Quality is always non-negative and can vary over a continuous support, so that $q \in[0,+\infty)$. The cost of providing quality, given by $\psi(q)$, is increasing and convex in $q$ and such that $\psi(0)=0$.

The value of the project to the buyer is given by $v+\nu(q)$, that is, the intrinsic value of the project plus the value of its quality. By normalising the value of quality so that $\nu(q)=q$, we can write the utility of the buyer as $U(v, q, p)=v+q-p$, where $p$ is the price paid to the contractor. To focus on situations in which the provision of quality is (socially) beneficial, we assume that the value of quality is always sufficiently high relatively to its cost; that is, we focus on cases in which $q \leq \bar{q}$, where $\bar{q}$ is such that $\bar{q}=\psi(\bar{q})$. Moreover, $v$ is always sufficiently high to induce the buyer to procure the project, that is, we assume that the buyer is willing to trade with the winning firm in any single period, thus ensuring that the buyer's participation constraint is always fulfilled. To ensure this, we assume that $v \geq \bar{v}$, where the actual value of $\bar{v}$ will be discussed later in the paper as it turns out not to be exogenously dependent on the model's parameters only. Conditional on being selected, firm $i$ 's profit is given by $\pi_{i} \equiv \pi(p, q)=p-\theta_{i}-\psi(q)$. Both firms have a reservation value equal to 0 and no possibility of making use of the capital markets, so that a non-negativity constraint holds for them in each period. ${ }^{17}$ All players are risk-neutral and have a common discount factor equal to $\delta$, where $\delta \in[0,1]$, capturing their time preference and the uncertainty about the existence of future opportunities of trade.

The competitive tendering and the scoring rule. In each period, the buyer awards the project by means of a scoring auction. Firms bear no bidding costs. ${ }^{18}$ Before bids are submitted, the buyer assigns to each firm a handicap and, once the bids are made, evaluates them in a discriminatory way, depending on the handicap. More specifically, for $i, j=1,2$ and $i \neq j$, the competitive procedure requires the buyer to announce the handicaps to the two firms, $h_{i}$ and $h_{j}$, and each firm to submit a bid, denoted as $b_{i}$ and $b_{j}$. Firms submit mono-dimensional bids, which comprise

\footnotetext{
${ }^{16}$ A separable cost function is also used by Asker and Cantillon (2010) and Calzolari and Spagnolo (2013).

${ }^{17}$ In the context of a repeated procurement market, Arve (2014) studies the case of financially constrained firms.

${ }^{18}$ In our stylised procurement market, competitors can be easily thought of as big-sized firms for which bidding costs are of a much lower order of magnitude than the value of the procurement contract.
} 
only the price dimension, but not the quality to be delivered. This is due to the fact that quality is non-contractible (as discussed below) and, thus, cannot be part of the submitted tender. ${ }^{19}$ In each competitive procedure, the buyer evaluates the bids using a scoring rule $S\left(b_{i}, h_{i}\right)$ and awards the contract to the lowest-score firm. Although bids are mono-dimensional, the scoring rule is needed to reflect the handicap imposed on the firm: a handicap $h_{i}$ is simply a non-negative real number to be added to the firm's bid. ${ }^{20}$ Formally, firm $i$ 's score is given by $S\left(b_{i}, h_{i}\right)=b_{i}+h_{i}$. In case of a tie - that is, if $S\left(b_{1}, h_{1}\right)=S\left(b_{2}, h_{2}\right)$ - we assume that the buyer awards the project randomly.

Informational structure. We analyse a game of perfect monitoring and incomplete information. Perfect monitoring relates to the fact that each player can observe the other players' actions. More specifically, the firms' handicaps and bids, the quality provided by the contractor and the final price are all perfectly observable by all players. Incomplete information relates to the buyer not knowing the realisation of the firms' (fixed) cost parameters. Each firm, instead, knows its own and the rival's cost. Although perfect monitoring implies that the buyer can fully observe the contractor's quality choice, this is not enforceable by a court of law, which implies that the buyer cannot make the contractual price conditional on the level of quality delivered.

This stylised informational structure allows us to focus on our research questions. The buyer's incomplete information on the firms' costs ensures that she faces two problems simultaneously: selecting the most efficient firm and inducing it to provide the required quality level. Moreover, full information between the firms ensures a tractable setting for our repeated competitive tendering model. ${ }^{21}$ Finally, thanks to the structure of our repeated game, perfect monitoring between the two firms is an innocuous assumption: only the handicaps applied to the two firms, rather than their past choices, matter for their decisions.

The timing of the game. We analyse an infinitely repeated game resulting from an infinite repetition of a sequential stage game. The timing of the stage game is as follows:

stage 1: the buyer sets the desired quality level $q_{i}$ and the handicap $h_{i}$ to each firm $i$, for $i=1,2 ;^{22}$

stage 2 (the bidding stage): firms learn their cost parameters and submit their bids, and the project is awarded by means of a sealed-bid lowest-score auction;

\footnotetext{
${ }^{19}$ If a bid were also to include a quality dimension (and quality were bounded from above), both firms would always find it optimal to bid the highest possible level of quality, wiping out all the effects of the quality component in the bids.

${ }^{20}$ Scoring rules are typically used to evaluate tenders with multiple attributes (say, quality and price). Che (1993) proves that a scoring auction in which price enters linearly into the scoring rule implements the optimal (buying) scheme when (firms') private information is one-dimensional. Asker and Cantillon (2008) extend this result to the case in which firms' private information is multidimensional. Our approach is in line with Burguet and Che (2004), who assume the bid to be only on verifiable elements of the firm's actions (in their paper, price and quality) and the scoring rule to reflect a possible discretionary bias of the buyer towards either firm.

${ }^{21}$ Under some restrictions, we show that assuming imperfect information between the firms does not alter the qualitative nature of most of our results. Details are omitted and are available from the authors upon request.

${ }^{22}$ In real procurement markets, the announcement of the desired quality level is normally part of the Terms of Reference, which describe the main technical characteristics of the project.
} 
stage 3 (the execution stage): the contractor chooses the quality level and delivers the project. The buyer pays the contractor a price equal to the contractor's bid, quality is observed and payoffs are collected.

\section{Equilibrium analysis}

We now analyse the game described in the previous section. We start by characterising the optimal quality level for the buyer. We then analyse the constituent game and show that, in equilibrium, the buyer is unable to induce the provision of any quality different from 0 . We then analyse the dynamic game under the two alternative assumptions of players using grim trigger and stick-andcarrot strategies; in both cases, we derive the conditions under which the buyer is able to obtain the provision of quality.

\subsection{Optimal quality}

We denote by $q^{*}$ the buyer's optimal quality level. Assuming that firm $i$ completes the project, $q^{*}$ maximises the buyer's utility $v+q-p$, subject to a non-negativity constraint on the firm's profits - i.e., $p-\theta_{i}-\psi(q) \geq 0$. Then, $q^{*}$ is implicitly defined by the condition $\frac{\partial \psi\left(q^{*}\right)}{\partial q^{*}}=1$, provided that $\psi\left(q^{*}\right)<q^{*}$. This is the standard optimality condition for quality, where marginal cost and marginal benefit are equated. Notice that, because of the separability in the firms' cost function, the optimal quality level is independent of the realisation of the firms' cost parameters.

\subsection{The static game}

We turn now to the analysis of the constituent game described in Section 3. It is useful to first concentrate on the bidding stage. Let $q_{i}^{\prime}$ and $q_{j}^{\prime}$ be the anticipated quality levels to be offered by firm $i$ and $j$ at the execution stage, respectively. Also, let $c_{i} \equiv c\left(\theta_{i}, q_{i}^{\prime}\right)$ and $C_{i} \equiv c_{i}+h_{i}$, where $C_{i}$ denotes firm $i$ 's 'perceived' cost, defined as the sum of the firm's anticipated cost, given $q_{i}$, and its handicap. Then, we can characterise the optimal pair of bids as follows:

Lemma 1. The optimal bids $b_{i}^{\prime}$ and $b_{j}^{\prime}$ at the bidding stage of the static game are:

i) if $C_{i}<C_{j}$, then $b_{i}^{\prime}=c_{j}+\left(h_{j}-h_{i}\right)$ and $b_{j}^{\prime}=c_{j}$, and firm $i$ is awarded the contract at a price $b_{i}^{\prime}$; ii) if $C_{i}=C_{j}$, then $b_{i}^{\prime}=c_{i}$ and $b_{j}^{\prime}=c_{j}$, and the project is randomly awarded to either firm at a price $b_{i}^{\prime}=b_{j}^{\prime}$.

This result implies that, in a static game, firms bid as in a standard, possibly asymmetric, Bertrand game, where, however, the firms evaluate their relative efficiency taking into account their 'perceived' costs. This is composed of three separate elements: first, the firms' fixed costs, $\theta_{i}$ and $\theta_{j}$; second, the cost of the quality levels that the two firms anticipate to deliver if they win the competitive tendering, $\psi\left(q_{i}\right)$ and $\psi\left(q_{j}\right)$; and, finally, the handicaps $h_{i}$ and $h_{j}$ imposed on the two firms. To illustrate, take the case of firm 1 having a fixed cost lower than the rival. If both firms anticipate to provide no quality and have a handicap equal to 0 , firms 1 bids to exploit 
its competitive advantage. If, instead, firm 1 anticipates to provide some positive quality, when the quality to be provided (and its cost) is too large relatively to the fixed cost differential (i.e. $\psi\left(q_{1}\right)>\Delta \theta$ ), it is now firm 2 which is able to outbid the rival and profit from its cost advantage. In the case of no (anticipated) quality, but positive handicaps to both firms, firm 1 enjoys a bidding advantage provided that $h_{1}-h_{2}<\Delta \theta$; if the direction of this inequality is reversed, firm 2 has a lower 'perceived' cost, can outbid the rival and win the auction. Notice that, since the handicap enters the scoring rule linearly, only the difference between the two handicaps is reflected in the equilibrium bids and then in the buyer's utility.

Characterising the equilibrium of the game is now a trivial exercise. At the execution stage, the contractor delivers zero quality. At the bidding stage, firms bid as in Lemma 1, anticipating that they will deliver no quality. If two firms face different 'perceived' costs - that is, if $C_{i} \neq C j$ - then whichever firm enjoys the overall competitive advantage will be awarded the contract at a price marginally below the opponent's 'perceived' cost, reduced by its own handicap. If the two firms face the same 'perceived' cost, then the contract will be awarded randomly. Since firms' 'perceived' cost are increasing in the difference between the handicaps, the buyer optimally sets the same handicap to both firms and picks any quality level, anticipating that it will not be delivered. This analysis trivially shows that, in a static setting, firms do not have an incentive to provide quality.

\subsection{The dynamic game}

We turn our attention to the dynamic game. In this game, an RPC describes, for any history of the game, the handicap that the buyer sets to a firm, the bid that this firm submits and the quality that it chooses, if awarded the contract. A pair of RPCs is self-enforcing if it describes a perfect equilibrium of the game. This type of game clearly has multiple equilibria. ${ }^{23}$ We concentrate our analysis on players adopting the following strategies:

Buyer: for $i=1,2$, the buyer sets $h_{i}=h_{B, i}^{C}$ to firm $i$ if: $i$ ) firm $i$ delivered quality equal to $q_{B, i}^{C}$ in all previous periods in which it was awarded the project (if any); or ii) firm $i$ delivered quality different from $q_{B, i}^{C}$ in some past periods, followed by $T_{B, i}$ periods in which it offered quality equal to $q_{B, i}^{P}$ when awarded the contract. Otherwise, the buyer sets $h_{i}=h_{B, i}^{P}$ to firm $i$.

Firm $i(i=1,2)$ : firm $i$ bids as in Lemma 1 with $q_{i}=q_{i}^{C}$ and, if awarded the project, offers quality $q_{i}^{C}$ if $\left.i\right) h_{i}=h_{i}^{C}$ in the current and all previous periods, or $i$ ) the buyer sets $h_{i} \neq h_{i}^{C}$ in some past periods, followed by $T_{i}$ periods in which it sets $h_{i}=h_{i}^{P}$. Otherwise, the firm bids as in Lemma 1 with $q_{i}=q_{i}^{P}$ and, if awarded the project, delivers quality $q_{i}^{P}$.

\footnotetext{
${ }^{23}$ Mailath and Samuelson (2006) provide an excellent and comprehensive treatment of repeated games.
} 
These strategies encompass, for different values of the length of the punishment period, both grim trigger and stick-and-carrot strategies.

Let $s_{B}$ and $s_{i}$ denote the strategy of the buyer and of firm $i$, respectively. With the unrestricted strategy domain implied in the above description, the buyer's and firm $i$ 's strategies may be denoted as $s_{B}\left(h_{B, 1}^{C}, h_{B, 2}^{C}, h_{B, 1}^{P}, h_{B, 2}^{P}, q_{B, 1}^{C}, q_{B, 2}^{C}, q_{B, 1}^{P}, q_{B, 2}^{P}, T_{B, 1}, T_{B, 2}\right)$ and $s_{i}\left(q_{i}^{C}, q_{i}^{P}, h_{i}^{C}, h_{i}^{P}, T_{i}\right)$, respectively. In the rest of the paper, however, we will focus on the buyer's strategies whereby she sets identical 'cooperative' and 'punitive' handicaps and quality levels to both firms, as well as an equal length of the punishment period. There are several reasons for focussing on 'symmetric' strategies. The first has to do with the fact that a public buyer, even if she has the ability to impose a handicap based on unverifiable elements of the firms' performance, should conform her behaviour to the general principle of 'equality of treatment': since the two firms are ex-ante identical, a buyer's strategy allowing for, say, different 'punitive' handicaps to the two firms would clearly violate this principle (the same reasoning applies to the other arguments of $s_{B}($.$) ). More-$ over, the hypothesis that our buyer requires the same 'cooperative' quality level to both firms is in line with our focus on the buyer's ability to induce the provision of the optimal quality level, which is identical across firms. A more fundamental reason for focussing on 'symmetric' strategies is related to the effect of the handicap on the buyer's utility and the sustainability of cooperation. In the discussion following Lemma 1 we emphasised that the buyer's utility is decreasing in the difference between the firms' handicaps; hence, along the equilibrium path of the game, the buyer strictly prefers those equilibria in which firms have symmetric 'cooperative' handicaps. Such an argument cannot, in principle, be applied to 'punitive' handicaps; these are not applied on the equilibrium path and therefore do not enter the buyer's utility. However, symmetric 'punitive' handicaps make an equilibrium easier to sustain, that is, they (weakly) enlarge the range of the discount factor ensuring its existence. ${ }^{24}$

We can then denote the players' strategies as follows:

$$
s_{B}\left(h_{B}^{P}, q_{B}^{C}, q_{B}^{P}, T_{B}\right) \text { and } s_{i}\left(q_{i}^{C}, q_{i}^{P}, h_{i}^{P}, T_{i}\right) \text {, for } i=1,2,
$$

where we also drop the relationship to $h_{B}^{C}$ and $h_{i}^{C}$ which, w.l.o.g., we normalise to 0 .

In the rest of the analysis, we assume that the buyer is committed to her strategy, that is, she cannot modify her punishment strategy during the play of the game. This implies that a pair of RPCs is self-enforcing when firms' strategies are part of of subgame perfect equilibrium of the repeated game given the buyer's strategy. ${ }^{25}$

\footnotetext{
${ }^{24}$ The intuition for this comes from the initial consideration that a firm's handicap negatively affects its critical discount factor via the effect on its continuation payoff after a deviation. Start from a situation in which neither firm has deviated in the past and both are threatened to be applied the same handicap in case of a deviation; decreasing marginally the 'punitive' handicap to one firm only pushes up the critical discount factor of this firm, making in turn cooperation more difficult to sustain.

${ }^{25}$ This is an extreme form of commitment; other weaker forms of commitment are, in principle, possible. For instance, one could envisage a buyer who commits to the level of the handicap or the length of the punishment period, but who can nonetheless deviate from her strategy by applying these punishments even on the absence of a deviation or not applying these punishments in case of a deviation. For any, however mild, departure from the assumption of full commitment, a pair of RPCs would be self-enforcing when the firms' and the buyer's strategies
} 


\subsubsection{Grim trigger strategies}

We start our analysis of the dynamic game by looking at the case of players using an infinitely long punishment when another player deviates. Formally, in the strategies described in the previous section, this simply accounts for deleting items ii) in the specification of the buyer's and firms' strategies or, equivalently, setting $T_{B}=T_{i}=\infty$.

In studying the game, we need to take into account that players may deviate from their strategies in many different ways. The possibility of the buyer deviating from her strategy is precluded by the hypothesis of commitment. Firms, instead, may deviate in two ways. First, the firm awarded the contract may decide to deliver at the execution stage a quality different from the one prescribed by its strategy $s_{i}($.$) . Notice that, since the project has a fixed nature and$ quality is costly, a firm does not gain from offering a positive quality level, with the exception of the long-term gains when it offers the 'cooperative' quality. As a consequence, a firm that chooses to deviate at the execution stage will always provide quality equal to 0 . This, in turn, implies that, despite the continuous range over which quality may be chosen, the only quality levels that a firm can profitably choose are either the one required by the buyer or 0 . The second possible type of deviation may occur at the bidding stage: anticipating that it will cheat on quality if it is awarded the contract, a firm may bid aggressively, making a bid that does not include the cost of quality.

Formally, the attention to grim trigger strategies and to the case of a committed buyer implies that, when referring to the buyer's strategy in (1), we can drop the functional relationship to $q_{B}^{P}$ and $T_{B}$. This is because $T_{B}$ is always set equal to $\infty$, and, since this strategy is unforgiving, there is no quality level that the buyer can prescribe during the punishment phase to terminate it. Thus, we can simply write the buyer's strategy as $s_{B}\left(h_{B}^{P}, q_{B}^{C}\right)$. Also, when referring to the firms' strategy in (1), we can simply write $s_{i}\left(q_{i}^{C}\right)$ and drop the functional relationship to $q_{i}^{P}, h_{i}^{P}$ and $T_{i}$ : indeed, the assumption of a committed buyer implies that we need not characterise the punishment phase by the firm.

We can then state the following result:

Proposition 1. Let

$$
\bar{\delta}\left(\psi\left(q^{*}\right)\right) \equiv \frac{\psi\left(q^{*}\right)}{\psi\left(q^{*}\right)+\beta(1-\beta) \min \left\{h^{\circ}-\psi\left(q^{*}\right), \Delta \theta\right\}} .
$$

Then, for any $h^{\circ} \geq \psi\left(q^{*}\right)$, and provided that $\delta \geq \bar{\delta}\left(\psi\left(q^{*}\right)\right)$, the strategy profile $s_{B}\left(h^{\circ}, q^{*}\right)$ and $s_{i}\left(q^{*}\right)$ (for $\left.i=1,2\right)$ defines a pair of self-enforcing RPCs whereby the project is awarded in each period to the most efficient firm, which delivers quality $q^{*}$.

In each period, the buyer's expected utility is $u=v+q^{*}-\psi\left(q^{*}\right)-\theta_{H}+\beta^{2} \Delta \theta$, and the expected value of firm $i$ 's profits is $E \pi_{i}=\beta(1-\beta) \Delta \theta$, with $i=1,2$.

are part of a subgame perfect equilibrium of the repeated game. 
The Proposition illustrates that a pair of RPCs with a sufficiently high handicap is able to induce the provision of the optimal quality level, provided that the firms value the future high enough. ${ }^{26}$ This result is illustrated in Figure 1, where the grey area shows the combinations of discount factor and handicap under which an equilibrium exists. The intuition for this result is fairly simple. Each firm knows that, when winning the competitive tendering and providing quality, it can make profits whenever nature makes it the most efficient firm. When, instead, a winning firm does not provide quality, the handicap puts it at a disadvantage relative to its rival in future repetitions of the game, reducing the stream of future profits; the higher the handicap, the larger the loss of future profits. Hence, for a given gain from a deviation due to current savings in the cost of quality, a high enough handicap can make the future value of cooperation larger than the future value of a deviation from the relational contract. ${ }^{27}$

While relegating the details of the proof to the Appendix, we provide here the main logical steps when $h^{\circ}>\psi\left(q^{*}\right)+\Delta \theta$, that is, in the case when either firm, if handicapped, will never have a chance to win any competitive tendering in future repetitions of the game (debarment). Given the buyer's strategy, consider firm $i$ 's problem $(i=1,2)$ at time $t=0$ whether or not to adhere to the 'cooperative' strategy, given that firm $j$ sticks to its 'cooperative' strategy. In each period, firm $i$ 's incentive compatibility (IC) constraint writes

$$
\pi_{i}^{C}+\frac{\delta}{1-\delta} E \pi_{i}^{C} \geq \pi_{i}^{D}+\frac{\delta}{1-\delta} E \pi_{i}^{P}
$$

where $\pi_{i}^{C}\left(\pi_{i}^{D}\right.$, respectively) are the current profits that firm $i$ makes when sticking to (deviating from) its strategy $s_{i}\left(q_{i}^{C}\right) ; E \pi_{i}^{C}\left(E \pi_{i}^{P}\right.$, respectively) are the expected single-period profits that it makes from the next period onwards when sticking to (being punished after a deviation from) strategy $s_{i}\left(q_{i}^{C}\right)$. This IC constraint can be re-written as

$$
\delta \geq \frac{\pi_{i}^{D}-\pi_{i}^{C}}{\left(\pi_{i}^{D}-\pi_{i}^{C}\right)+\left(E \pi_{i}^{C}-E \pi_{i}^{P}\right)} .
$$

Notice first that $E \pi_{i}^{C}=\beta(1-\beta) \Delta \theta$, namely the value of the profit in an asymmetric Bertrand game times the probability that firm $i$ is the low-cost firm, while firm $j$ is the high-cost firm, is identical for all possible realisations of the cost parameters. Second, $E \pi_{i}^{P}$ is simply 0 due to the buyer's commitment to punish any deviation from the cooperative path with a handicap large enough so that a deviating firm will not be able to win any contract in the future. Consequently, the most stringent value of the discount factor for cooperation to be sustainable is obtained by solving for the highest possible value of the difference $\left(\pi_{i}^{D}-\pi_{i}^{C}\right)$, namely the static net gain from

\footnotetext{
${ }^{26}$ These conditions are necessary and sufficient for a pair of self-enforcing RPCs, given our restriction to the strategies described at the beginning of Section 4.3. The same applies to the result given in Proposition 2.

${ }^{27}$ In a different context, Cesi et al. (2012) show that relational contracting induces optimal unverifiable quality by a regulated firm. The authors study a regulatory relational contract between a fully informed regulator and a monopolistic supplier whose quality is unverifiable. The regulator may induce the firm to deliver the socially efficient quality by allowing prices above the Ramsey level, so that a positive rent is left to the firm, as long as the required quality is produced.
} 
a deviation, across all possible realisations of the firms' cost parameters. It can be shown that this value is at most equal to $\psi\left(q^{*}\right)$, which coincides with the value of savings from not delivering quality at the execution stage. Thus the critical threshold in (3) becomes $\frac{\psi\left(q^{*}\right)}{\psi\left(q^{*}\right)+\beta(1-\beta) \Delta \theta}$ as in (2).

If $\psi\left(q^{*}\right)<h^{\circ}<\psi\left(q^{*}\right)+\Delta \theta$, during the play of the subgame unfolding after a deviation, the deviating firm may in principle be able to win a contract depending on the cost configurations and the other firm's strategy whether or not to deliver quality. This implies that $E \pi_{i}^{P}$ will be different from 0 . However, the proof shows that the condition to hold is still the one in (3), since the critical discount factor ensuring that a non-deviating firm will optimally cooperate in the subgame unfolding after the rival's deviation is always lower than the critical discount factor at the beginning of the whole game when neither firm is handicapped.

A noticeable feature of our equilibrium is that the handicap plays a role only off the equilibrium path. The first consequence is that, in equilibrium, firms only bid according to their costs. Hence, the buyer is able to obtain quality without leaving any extra rent to the firms - that is, any profits in excess of what they would make in a static competitive tendering when quality is verifiable. Second, there exists in principle a continuum of values of the handicap supporting an equilibrium. In particular, the buyer is able to obtain her desired quality without necessarily threatening to debar a deviating firm from the market. Indeed, the deviating firm is debarred only when $h^{\circ}>\psi\left(q^{*}\right)+\Delta \theta$, as shown in region B in Figure $1 .{ }^{28}$ When, instead, the handicap is not so high, as in region $\mathrm{A}$ in Figure 1, the deviating firm suffers from a milder punishment, which allows it to be awarded the project when that firm is more efficient than its competitor.

A third consequence is that the buyer's utility remains constant among all possible equilibrium values of the handicap, so that she can achieve the same level of expected utility by resorting to quite a large set of handicap levels. In other words, since the buyer always prefers the cooperative equilibrium to the situation in which no quality is provided, all the equilibrium values of $h^{\circ}$ are equally optimal. Thus, our model, as it stands, cannot then address the issue of the buyer's selection criterion of the (equilibrium) handicap level; different levels of the handicap (above a given threshold) only make the conditions for the existence of an equilibrium more or less stringent, in that a high (low, respectively) handicap enlarges (reduces) the range of values of the discount factors which make cooperation possible. On the other hand, it is possible to argue that if our model were extended to take into account some additional features, it would emerge the preference of the buyer towards lower levels of the handicap. If our model included the possibility of an imperfectly observable or stochastic quality or of a 'tremble' in the players' choice of action, the punitive phase (and the handicap level) would begin to play a role in the equilibrium buyer's utility. In these cases, if an equilibrium were to exist, then our conjecture is that it should imply

\footnotetext{
${ }^{28}$ Consistently with our assumption of no bidding costs, we assume that a firm with a large handicap (say, firm $j$ ) keeps participating in the competitive tendering even if it can never outbid the rival. Alternatively, we could assume that firm $j$ refrains from bidding, although standing ready to participate in the auction if there are profitable opportunities. In this case, firm $i$ 's optimal bid would be such that it makes firm $j$ indifferent between staying out and entering the auction; however, this bid is identical to the one that firm $i$ would make if firm $j$ decided to bid. In other words, even if firm $j$ stays out when harshly handicapped, the amount of surplus that firm $i$ can extract is limited by the threat of firm $j$ being willing to enter and bid when it can profitably undercut firm $i$.
} 
the lowest handicap compatible with the firms' incentive to play cooperatively. This is because, whenever $\psi(q) \leq h^{\circ}$ (as required in equilibrium in our model), it is easy to show that $\frac{\partial E U(.)}{\partial h}<0$ when one firm only is punished and $\frac{\partial E U(.)}{\partial h}=0$ when both are punished. The reason for this result is quite simple: a larger handicap typically increases the asymmetry between the firms, thus allowing the contractor a larger rent.

Two additional features of our equilibrium stand out. First, all combinations of the handicap and the discount factor that meet the conditions stated in Proposition 1 are able to sustain an equilibrium; this implies that, if we interpret the discount factor as a parameter depending on the frequency of interactions - which is one of the buyer's decisions in real procurement markets - the buyer has the ability to substitute between the two instruments of the handicap and the frequency of interactions. This result is rather standard in the repeated game literature (see Shapiro, 1983, but also, more recently, Iossa and Rey, 2014). Notice, however, that in our model, since neither firm is ever handicapped along the equilibrium path, the buyer does not have an incentive to exploit this substitutability. Second, the level of the handicap able to induce the delivery of quality is unrelated to the utility derived from quality and depends on the firms' costs only. In other words, for a handicap to be effective in inducing the delivery of quality, it must be set not in relation to the buyer's loss of utility due to the lower quality level, but to the effect that the handicap has on the firms' incentives. ${ }^{29}$

The main features of the RPC just discussed allow us to pin down the value of $\bar{v}$, that is, the minimum intrinsic value of the project. This condition on $v$ ensures that the buyer always prefers to procure the object. Clearly, it must hold not only on the equilibrium path, when neither firm is handicapped, but also off the equilibrium path, when at least one of the two firms is handicapped. Since the cost of the project to the buyer increases proportionally with the degree of asymmetry between firms, the condition on $v$ must be determined when the degree of asymmetry is the largest, something which occurs when only one of the two firms is handicapped. In this situation, the handicap imposed to one firm is also a measure of the (potentially additional) competitive advantage, and therefore of the rent, to its rival. Therefore, we conclude that $v \geq \bar{v} \equiv \theta_{H}+h^{\circ}$; the first term in $\bar{v}$ measures either firm's most unfavourable fixed cost and the second term captures the rent. Therefore, this value of $\bar{v}$ sets out the most unfavourable market conditions and ensures that the buyer is willing to procure the project in any period.

\subsubsection{Stick-and-carrot strategies}

Grim trigger strategies entail an everlasting punishment, which may not be fully convincing in public procurement, as a public buyer may not be willing to renounce her desired quality forever. Stick-and-carrot strategies are, instead, forgiving and, thus, more palatable since they allow for a punishment of limited length. In this section, we assume that players use stick-and-carrot strate-

\footnotetext{
${ }^{29}$ It is possible to show that an identical result could be obtained if we had assumed different tie-breaking rules, under which, in case of a tie in the firms' scores, the project would be awarded to the lowest bid or, alternatively, to the firm with the lowest handicap. The same applies to Proposition 2.
} 


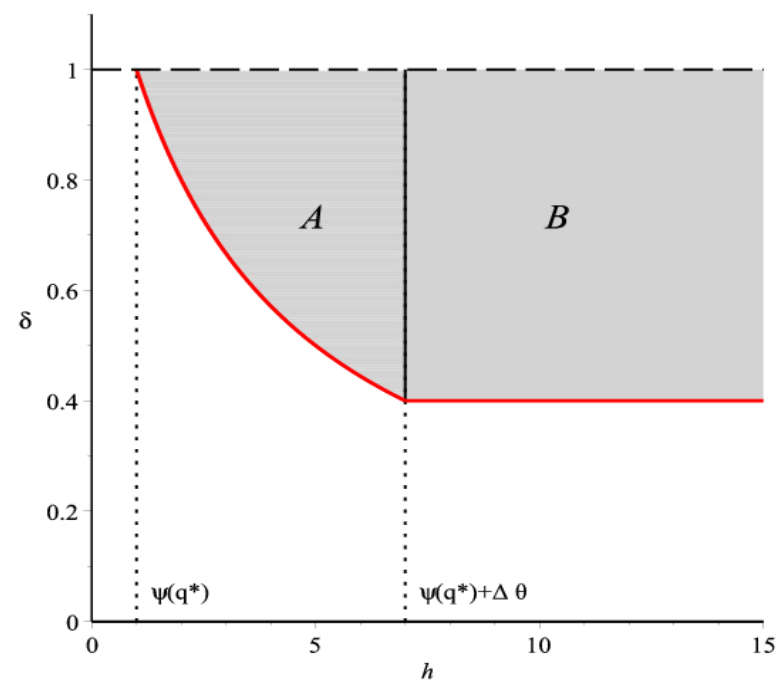

Figure 1: Equilibrium combinations of handicap and discount factor with grim trigger strategies (when $\beta=0.5, \psi\left(q^{*}\right)=1$ and $\Delta \theta=6$ )

gies: any deviating player is punished for a limited number of periods, provided that it maintains an appropriate behaviour during this punishment phase. When referring to these strategies, we will denote the buyer's strategy as in (1) - i.e., by $s_{B}\left(h_{B}^{P}, q_{B}^{C}, q_{B}^{P}, T_{B}\right)$ - where, unlike what we did in the previous section, we maintain the functional relationship to the variables characterising the time-limited punishment phase. Regarding firm $i$ 's strategy, as in the previous section, we write it as $s_{i}\left(q_{i}^{C}\right)$; as already stated in Section 4.3.1, our assumption of a committed buyer implies that we need not characterise the punishment phase by the firm.

In the rest of this subsection, we concentrate on the case of the discount factor arbitrarily close to 1 . This simplifies the technical analysis and is less restrictive than it appears: if an equilibrium exists when $\delta \rightarrow 1$, by continuity, there always exists a critical discount factor sufficiently close to 1 , but strictly smaller than 1 , such that a self-enforcing pair of RPCs exists. ${ }^{30}$ Also, we restrict our analysis to the case in which, during the punishment phase, the buyer's stick-and-carrot strategy entails a quality level equal to 0 (i.e., $q_{B}^{P}=0$ ), so that the quality level required after a deviation is lower than in equilibrium. ${ }^{31}$ We can now state the main result of this section.

Proposition 2. Assume that $\delta \rightarrow 1$. Let

$$
\bar{T} \equiv \max \left\{\frac{\psi\left(q^{*}\right)}{\beta(1-\beta) \min \left\{h^{\circ}-\psi\left(q^{*}\right), \Delta \theta\right\}}, 1\right\}
$$

\footnotetext{
${ }^{30}$ To provide further support to this approach, we explicitly derive the values of the critical discount factor which ensure the existence of an equilibrium for specific values of $T_{B}$. This analysis confirms that, under rather mild parametric conditions, the critical discount factors are strictly smaller than 1.

${ }^{31}$ Other punishments are, in principle, possible. For instance, a continuity argument might be used to argue that a pair of self-enforcing RPCs can be supported by a $q_{B}^{P}$ strictly greater than but sufficiently close to 0 . On the other hand, a very large $q_{B}^{P}$ will necessarily induce a deviation from the punishment phase. This leads to the conclusion that there exists a maximum level of $q_{B}^{P}$ compatible with the existence of an equilibrium. Assuming $q_{B}^{P}=0$ has the clear advantage of simplifying the analysis of the dynamic game, since no deviation is possible from the punishment phase.
} 


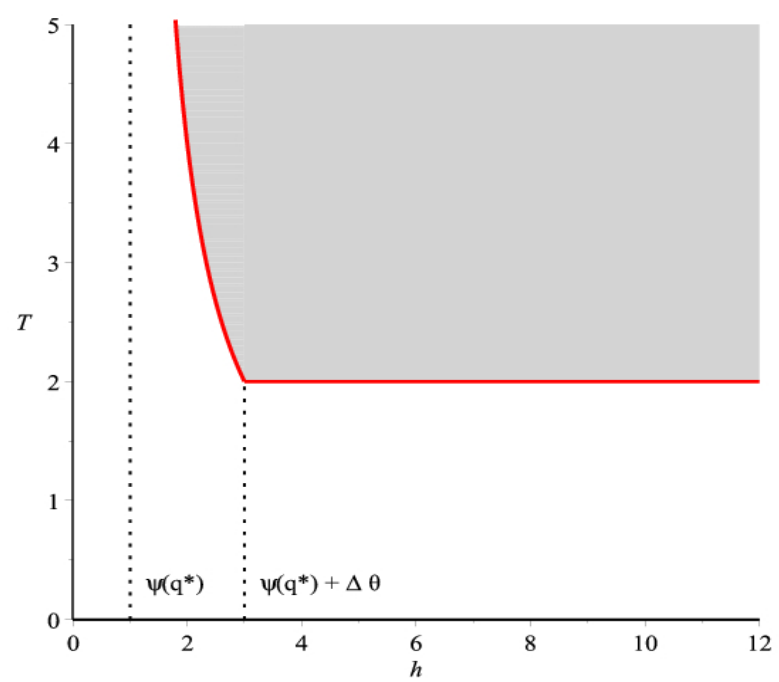

Panel A: the case of $\psi\left(q^{*}\right)<\beta(1-\beta) \Delta \theta$

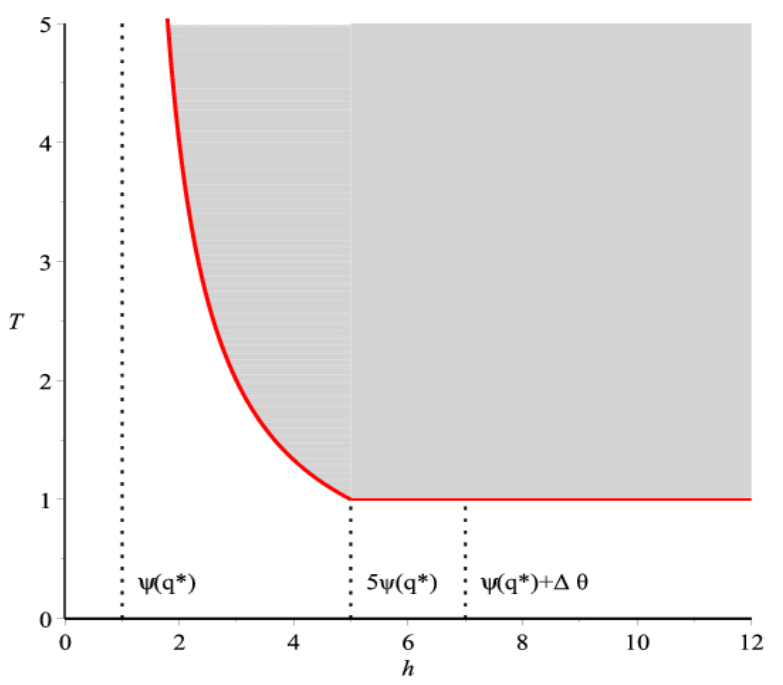

Panel B: the case of $\psi\left(q^{*}\right) \geq \beta(1-\beta) \Delta \theta$

Figure 2: Equilibrium combinations of handicap and punishment length with stick-and-carrot strategies (when $\beta=0.5$ and $\psi\left(q^{*}\right)=1$, and $\Delta \theta=6$ in panel A and $\Delta \theta=2$ in panel B).

Then, provided that $h^{\circ} \geq \psi\left(q^{*}\right)$ and $T^{\circ} \geq \bar{T}$, the strategy profile $s_{B}\left(h^{\circ}, q^{*}, 0, T^{\circ}\right)$ and $s_{i}\left(q^{*}\right)$ (with $i=1,2)$ defines a pair of self-enforcing RPCs whereby the project is awarded in each period to the most efficient firm, which delivers quality $q^{*}$.

In each period, the buyer's expected utility and the firms' profits are as in Proposition 1.

The Proposition illustrates that, when firms are close to be infinitely patient, it is possible to induce the delivery of quality even with a punishment of finite duration, provided that this lasts long enough. These combinations of handicap and punishment length inducing the delivery of quality are illustrated by the shaded areas in Figure 2, where panel A relates to the case of low quality cost (or, equivalently, to the case of a large fixed cost differential) and panel B to the case of high quality cost (or, equivalently, to the case of a small fixed cost differential). ${ }^{32}$

The intuition behind this result is straightforward. When the handicap is low, the punishment length and the handicap are substitutes for each other. The reason is that a low handicap makes a cheating firm still likely to be awarded the contract again when it is efficient, thus limiting the extent of its punishment. The punishment becomes effective only when it is long enough; however, any increase in the handicap allows the buyer to reduce the minimal punishment length, since it reduces the profits of the cheating firm when it is awarded the contract. When, instead, the handicap is sufficiently high, the cheating firm is debarred from the market. Since the debarment is the harshest form of punishment, the minimal punishment length is constant and no longer depends on the handicap. Thus, the substitutability between the punishment length and the

\footnotetext{
${ }^{32}$ As anticipated in footnote 30 , when $T_{B}=1$, our stick-and-carrot strategies are part of an equilibrium of our game when $\delta \geq \delta_{T_{B}=1} \equiv \frac{\psi\left(q^{*}\right)}{\beta(1-\beta) \mu}$, where $\mu \equiv \min \left\{h^{\circ}-\psi\left(q^{*}\right), \Delta \theta\right\} ;$ when $T_{B}=2$, the same applies when $\delta \geq \delta_{T_{B}=2} \equiv \frac{\sqrt{[\beta(1-\beta) \mu]^{2}+4 \beta(1-\beta) \psi\left(q^{*}\right) \mu}-\beta(1-\beta) \mu}{\beta(1-\beta) \mu}$. Notice that, as expected, $\bar{\delta}\left(\psi\left(q^{*}\right)\right)<\delta_{T_{B}=2}<\delta_{T_{B}=1}$, so that the longer the punishment period the lower the critical discount factor. Details are omitted and available from the authors upon request.
} 
handicap disappears. Finally, notice that, for any given handicap, the (minimal) punishment that induces cooperation is longer the higher the cost of quality. In other words, the set of equilibrium combinations of handicap and punishment length in panel B of Figure 1 is strictly contained by the similar set in panel $\mathrm{A}$. This is simply because, with a high quality cost, each firm has a higher incentive to deviate and, therefore, needs a longer punishment to be induced to stick to its cooperative strategy.

\section{Conclusions}

While advocated in terms of transparency and fairness, competitive procedures in public procurement are blunt in promoting quality provision at the execution stage, when quality is nonverifiable. In this paper, we have shown that an appropriately designed scoring auction, comprising both the price dimension and firms' past performance (through a handicap score), is instrumental in selecting the efficient supplier and in implementing the buyer's desired quality level. Most notably, and unlike the results in the related literature, we have characterised the circumstances under which a self-enforcing relational contracting does not necessarily exclude any competitor from the procurement market. By linking past performance to the score in the current competitive process, a buyer is able to provide contractors with dynamic incentives to provide quality. This seems to capture the spirit of the U.S. Federal Acquisition Regulation that deems past performance an important element of every evaluation and contract award.

Our analysis could be expanded in a number of directions. One, almost compelling, extension would point towards relaxing the assumption of a fully committed buyer. In section 4.3 we hinted at one possible way of weakening the full commitment assumption. The case of an uncommitted buyer also sounds appealing as it would better suit, for instance, a private buyer who is arguably less constrained than a public buyer. An uncommitted buyer will need to restrict herself to credible handicapping strategies, that is, both the firms' strategies and the buyer's handicapping strategy need to be part of a subgame perfect equilibrium of the repeated game. This requirement does in fact modify the set of conditions under which a relational contracting equilibrium exists. ${ }^{33}$

A second extension is driven by weakening the assumption of perfect observability of quality between trading parties at the execution stage of the procurement contract. ${ }^{34}$ Assume that the quality observed by the buyer does not necessarily allow her to infer the contractor's quality decision; this may be the result of the buyer just getting a signal, which is imperfectly correlated to the true quality level, or of the stochastic nature of the quality production process. An immediate observation is that the imperfect observability of the contractor's choice makes the cooperative equilibrium impossible to be sustained by means of grim trigger strategies. An equilibrium is likely to be sustained, instead, by stick-and-carrot strategies, arguably more appealing in (public) procurement markets. Under these strategies, our original model delivered a (certain degree of)

\footnotetext{
${ }^{33}$ The analysis of the case of an uncommitted buyer is carried out in a earlier version of this work. Details are available from the authors upon request.

${ }^{34} \mathrm{We}$ are grateful to one of the referees of this journal for raising this point.
} 
substitutability between the length and the harshness of the handicap. Imperfect observability might alter this substitutability in several different ways, potentially depending on the nature of the firm's deviation and on the industry environment (as described by the model's parameters), and would certainly deserve a dedicated line of research.

\section{References}

Acquisition Central, 1997. The White Paper, available at http://www.acquisition.gov/sevensteps/library/ ASIwp-past-perform.pdf.

Arve, M. 2014. "Procurement and Predation: Dynamic Sourcing from Financially Constrained Suppliers". Journal of Public Economics, 120, 157-168.

Asker, J. and E. Cantillon, 2008. "Properties of scoring auctions". RAND Journal of Economics, 39, 69-85.

Asker, J. and E. Cantillon, 2010. "Procurement when price and quality matter", RAND Journal of Economics, 41(1), 1-34.

Ayres, I. and P. Cramton, 1996. "Deficit Reduction Through Diversity: How Affirmative Action at the FCC Increased Auction Competition", Stanford Law Review 48(4), 761-815.

Auriol, E. and T. Søreide, 2015. "An Economic Analysis of Debarment". NHH Dept. of Business and Management Science Discussion Paper No. 2015/23.

Bajari, P., R. McMillan and S. Tadelis, 2009. "Auctions versus negotiations in procurement: an empirical analysis". Journal of Law, Economics \& Organization, 25, 372-399.

Baker, G., R. Gibbons and K. J. Murphy, 2002. "Relational contracts and the theory of the firm". Quarterly Journal of Economics, 117, 39-84.

Bigoni M., G. Spagnolo and P. Valbonesi, 2014. "Sticks and Carrots in Procurement: An Experimental Exploration". B.E. Journal of Economic Analysis 83 Policy, 14(3), 893-936.

Board, S., 2011. "Relational contracts and the value of loyalty". American Economic Review, 101, 3349-3367.

Boudreau, K., N. Lacetera and K. Lakhani, 2011. "Incentives and Problem Uncertainty in Innovation Contests: An Empirical Analysis". Management Science, 57(5), 843-863.

Branco, F., 1997. "The design of multi-dimensional auctions". RAND Journal of Economics, 28(1), 63-81.

Branco, F., 2002. "Procurement favouritism and technology adoption". European Economic Review, 46, 73-91.

Bull, C. 1987. "The existence of self-enforcing implicit contracts". Quarterly Journal of Economics, 102, $147-159$.

Burguet, R. and Y.-K. Che, 2004. "Competitive procurement with corruption". RAND Journal of Economics, 35, 50-68.

Calzolari, G. and G. Spagnolo, 2013. Relational Contracts and Competitive Screening, mimeo; previously appeared as CEPR Working paper no. DP7434, 2009.

Cesi, B., A. Iozzi and E. Valentini, 2012. "Regulating unverifiable quality by fixed-price contracts". BE Journal of Economic Analysis \& Policy, 40, 1-39.

Che, Y.-K., 1993. "Design competition through multi-dimensional auctions". RAND Journal of Economics, 24(4), 668-680.

Che, Y.-K., 2008. "Procurement". In: S. N. Durlauf and L. E. Blume (eds.), The New Palgrave Dictionary of Economics (2nd edition). The New Palgrave Dictionary of Economics Online. Palgrave Macmillan, available at: http://www.dictionaryofeconomics.com. 
Che, Y.-K. and D. B. Hausch, 1999. "Cooperative investments and the value of contracting". American Economic Review, 89, 125-147.

Che, Y.-K. and T. Gale, 2003. "Optimal design of research contests". American Economic Review, 93, 646-671.

Congressional Research Service, 2008. Debarment and Suspension of Government Contractors: An Overview of the Law Including Recently Enacted and Proposed Amendments, available at https:// www.fas.org/sgp/crs/misc/RL34753.pdf.

Dalen, D. M., E. Moen and C. Riis, 2006. "Contract renewal and incentives in public procurement". International Journal of Industrial Organization, 24, 269-285.

Dietz, R., 2002. "The FAR's Commercial Flexibility". Contract Management, 2002, 34-37.

Doni, N., 2006. "The importance of the reputation in awarding public contracts". Annals of Public and Cooperative Economics, 77, 401-429.

Estache, A., J. L. Guasch, Aİimi and L. Trujillo, 2009. "Multidimensionality and renegotiation: Evidence from transport-sector public -private-partnership transactions in Latin America". Review of Industrial Organization, 35(1), 41-71.

Fehr, E. and K. Schmidt, 2007. "Contracts and fairness: Adding a stick to the carrot? The interaction of bonuses and fines". American Economic Review, 97(2), 177-181.

Giebe, T. and P. Schweinzer, 2015. "Probabilistic Procurement Auctions". Review of Economic Design, $19,25-46$.

Hanazono, M., J. Nakabayashi and M. Tsuruoka, 2013. Procurement Auctions with General Price-Quality Evaluation. Kyoto Institute of Economic Research, Discussion Paper no. 845

Iossa, E. and P. Rey, 2014. "Building reputation for contract renewal: implications for performance dynamics and contract duration". Journal of the European Economic Association, 12, 549-574.

Kessler, A. S. and C. Lulfesmann, 2004. "Bilateral bargaining, unverifiable quality and options to return". Economic Theory, 23(3), 395-410.

Kim, I., 1998. "A model of selective tendering: does bidding competition deter opportunism by contractors?". Quarterly Review of Economics and Finance, 8, 907-925.

Klein, B. and K. Leffler, 1981. "The role of market forces in assuring contractual performance". Journal of Political Economy 89, 615-41.

Laffont, J.-J. and J. Tirole, 1993. A Theory of Incentives in Procurement and Regulation. MIT Press: Cambridge (MA).

Lalive, R. and A. Schmutzler, 2011. Auctions vs negotiations in public procurement: which works better?. Working paper n. 23, University of Zurich.

Levin, J., 2003. "Relational incentive contracts". American Economic Review, 93, 835-857.

Lewis R. and D. Sappington, 1991. "Incentives for Monitoring Quality". RAND Journal of Economics, $22(3), 370-384$.

Li, J. and N. Matouschek, 2013. "Managing Conflicts in Relational Contracts". American Economic Review, 103(6), 2328-2351.

Maasland, E., Y. Montangie and R. Van den Bergh, 2004. "Levelling the playing field in auctions and the prohibition of state aid". In M. C. V. Janssen (ed.), Auctioning Public Assets: Analysis and Alternatives, Cambridge (UK): Cambridge University Press.

MacLeod, W. B., 2003. "Optimal contracting with subjective evaluation". American Economic Review, $93,216-240$.

MacLeod, W. B. and J. M. Malcomson, 1989. "Implicit contracts, incentive compatibility, and involuntary unemployment". Econometrica, 57, 447-480.

Mailath, G. J. and L. Samuelson, 2006. Repeated Games and Reputations: Long Run Relationships, Oxford: Oxford University Press. 
Manelli, A. M. and D. R. Vincent, 1995. "Optimal procurement mechanisms". Econometrica, 63, 591-620.

Milgrom, P., 2004. Putting Auction Theory to Work. Cambridge: Cambridge University Press.

Naegelen, F. and M. Mougeot, 1998. "Discriminatory public procurement policy and cost reduction incentives". Journal of Public Economics, 67, 349-367.

Rayo, L., 2007. "Relational incentives and moral hazard in teams". Review of Economic Studies, 74, 937-963.

Shapiro C., 1983. "Premiums for high quality products as returns to reputations". Quarterly Journal of Economics, 98(4), 659-679.

Taylor, C. R., 1993. "Delivery-contingent contracts for research". Journal of Law, Economics \& Organization, 9, 188-203.

Tunca, T. I. and S. A. Zenios, 2006. "Supply auctions and relational contracts for procurement". Manufacturing $\& 3$ Service Operations Management, 8, 43-67.

U.S. General Services Administration, 2016. Federal Acquisition Regulation, Volume 1, available at https://www.acquisition.gov/?q=browsefar.

U.S. Government Accountability Office, 2011. Prior Experience and Past Performance as evaluation criteria in the award of Federal Construction Contracts (GAO-12-102R), available at http://www.gao.gov/products/GAO 12-102R.

U.S. Government Accountability Office, 2014. Federal Contracts and Grants Agencies Have Taken Steps to Improve Suspension and Debarment Programs (GAO-14-513), available at http://www.gao.gov/ products/GAO-14-513.

Vagstad, S., 1995. "Promoting fair competition in public procurement". Journal of Public Economics, 58, 283-307.

Wang, R. 2000. "Bidding and renegotiation in procurement auctions". European Economic Review, 44(8), $1577-1597$.

\section{Appendix}

We provide here the proofs of all Propositions in the paper. As a presentational device, the proofs illustrate the existence of an equilibrium at $t=0$ and checks for the profitability of a deviation by firm 1 ; due to ex-ante symmetry between the firms and the infinitely repeated nature of the game, the same arguments are valid for both firms at any repetition of the game.

To simplify the notation, we let $\psi^{*} \equiv \psi\left(q^{*}\right)$. We denote the four possible combinations of cost parameters realisations by $L L, H H, L H$ and $H L$, where the first letter refers to firm 1's fixed cost parameter, while the second letter to firm 2's one; for instance, we denote by $L H$ the case in which $\theta_{1}=\theta_{L}$ and $\theta_{2}=\theta_{H}$. Also, we let $\pi_{i}^{C}\left(h_{1}, h_{2}\right)\left(\pi_{i}^{D}\left(h_{1}, h_{2}\right)\right.$, respectively) be the profits that firm $i$ (with $\left.i=1,2\right)$ makes if it sticks to (deviate from, respectively) its strategy $s_{i}($.$) , where h_{1}$ and $h_{2}$ denote the handicap on firm 1 and 2, respectively. Let also $\pi_{i}^{P}\left(h_{1}, h_{2}\right)$ be the profits that firm $i$ (with $i=1,2$ ) makes when punished from a previous deviation from its strategy $s_{i}($.$) , where h_{1}$ and $h_{2}$ denote the handicap on firm 1 and 2 , respectively. The operator $E$ denotes the expected value of the firm's profits, where the expectaction is taken upon the possible realisations of the cost parameters.

We start by illustrating the optimal single-period best reply for firm $i$ when firm $j$ plays in the same period as prescribed by its cooperative strategy $s_{j}($.$) ; the following Lemma shows that this best reply$ depends on the realisation of the firms' cost parameters, the firms' handicaps, the quality level and its cost.

Lemma A-1. Consider the static game of Section 4.2. Assume the anticipated quality level for firm $j$ is $\bar{q}$ and that firm $j$ bids as in Lemma 1 and, if winning the auction, delivers quality $\bar{q}$. Then, for any $h_{i}$ and $h_{j}$, and any realisation of the firms' cost parameters,

i) the best reply for firm $i$ is as follows: 
i.i) if $c\left(\theta_{i}, \bar{q}\right)+h_{i}<c\left(\theta_{j}, \bar{q}\right)+h_{j}$, then firm $i$ bids as in Lemma 1, wins the auction and delivers quality equal to 0 ;

i.ii) if $c\left(\theta_{j}, \bar{q}\right)+h_{j} \leq c\left(\theta_{i}, \bar{q}\right)+h_{i}$ and $h_{i}-h_{j}<\theta_{j}-\theta_{i}+\psi(\bar{q})$, then firm $i$ bids $b_{i}=c\left(\theta_{j}, \bar{q}\right)+h_{j}-h_{i}<$ $c\left(\theta_{i}, \bar{q}\right)$, wins the auction and delivers quality equal to 0 ;

i.iii) if $c\left(\theta_{j}, \bar{q}\right)+h_{j} \leq c\left(\theta_{i}, \bar{q}\right)+h_{i}$ and $h_{i}-h_{j}=\theta_{j}-\theta_{i}+\psi(\bar{q})$, then firm $i$ bids $b_{i}=c\left(\theta_{j}, \bar{q}\right)+h_{j}-h_{i}<$ $c\left(\theta_{i}, \bar{q}\right)$, the two firms tie and, if firm $i$ is randomly selected, it delivers quality equal to 0 ;

i.iv) if $c\left(\theta_{j}, \bar{q}\right)+h_{j} \leq c\left(\theta_{i}, \bar{q}\right)+h_{i}$ and $h_{i}-h_{j}>\theta_{j}-\theta_{i}+\psi(\bar{q})$, then firm $i$ bids as in Lemma 1 and loses the auction.

ii) Relatively to the case in which firm i's strategy is identical to the one of firm $j$, the best reply described in i) ensures to firm $i$ a gain at most equal to $\psi(\bar{q})$.

Proof. $i$ ) In case $i . i)$, firm $i$ does not have any incentive to deviate from the bidding strategy described in Lemma 1. Upon winning, though, it may increase its profit by an amount of $\psi(\bar{q})$ by delivering zero quality. In case $i . i i)$, if firm $i$ bids according to Lemma 1 it would lose the auction thus getting a payoff equal to 0 . It can, instead, profitably bid (slightly below) $c\left(\theta_{j}, \bar{q}\right)+h_{j}-h_{i}$, thus winning the auction, and then delivers quality equal to 0 . This would yield a profit at most equal to $\psi(\bar{q})$. In case i.iii), again, if firm $i$ were to bid according to Lemma 1 it would lose the auction and thus gets a payoff equal to 0 . Firm $i$ may lower its bid by an amount equal to $\psi(\bar{q})$, which would make it tie with firm $j$, and, if selected, it delivers quality equal to 0 , thus recovering exactly $\psi(\bar{q})$. This strategy also yields firm $i$ profit equal to 0. Finally, in case $i . v$ ) firm $i$ 's competitive disadvantage with respect to firm $j$ is strictly greater than $\psi(\bar{q})$, thus the necessary bid reduction to win the auction cannot be recovered by delivering quality equal to 0 , which implies that firm $i$ bids as in Lemma 1.

ii) The analysis of the four cases in $i$ ) shows that firm $i$ 's highest possible gain from deviating from the strategy prescribed by Lemma 1 is bounded by $\psi(\bar{q})$.

Proof of Proposition 1. The proof analyses separately the possible subgames of our dynamic game. These subgames are referred to as $G\left(h_{1}, h_{2}\right)$, with $h_{1}, h_{2} \geq 0$, where the first (second, respectively) variable in brackets relates to the handicap imposed on firm 1 (firm 2 , respectively). For any $h>0$, the subgames are as follows: $i) G(0,0)$, when neither firm is handicapped (and the subgame coincides with the whole game); ii) $G(h, 0)$, when firm 1 deviated in the past and it is applied a strictly positive handicap in future repetitions of the game, whereas a handicap equal to 0 is applied to the rival firm, and $i i i) G(h, h)$, when both firms deviated in the past and are applied a strictly positive handicap in future repetitions of the game.

We start by focusing on the subgame $G(h, 0)$. We then make the following assumption:

Assumption 1. Consider the subgame $G\left(h^{\circ}, 0\right)$. Assume that the two firms behave as follows: firm 1 (e.g., the one with a positive handicap) always bids as in Lemma 1 with the intention to provide quality equal to 0 and, if awarded the project, provides quality equal to 0, and firm 2 always sticks to its cooperative strategy $s_{2}($.$) .$

This assumption allows us to characterise the firms' payoff in a subgame that, as we will show, is never played on the equilibrium path: later in the proof, we will then prove that the behaviour we assume in this subgame is indeed an equilibrium for any combination of the parameters for which neither firm prefers to deviate from its cooperative strategy $s_{i}($.$) at t=0$.

At $t=0$, the IC constraint for firm 1 can be re-written as

$$
\delta \geq \frac{\pi_{1}^{D}(0,0)-\pi_{1}^{C}(0,0)}{\left(\pi_{1}^{D}(0,0)-\pi_{1}^{C}(0,0)\right)-\left(E \pi_{1}^{P}\left(h^{\circ}, 0\right)-E \pi_{1}^{C}(0,0)\right)} .
$$

In (A-1), the expected profits expressions do not depend on the current realisation of the firms' cost 
parameters; using standard result on Bertrand game and Assumption 1, for any $h$ we can write

$$
\begin{aligned}
& E \pi_{1}^{C}(0,0)=\beta(1-\beta) \Delta \theta ; \\
& E \pi_{1}^{P}(h, 0)= \begin{cases}0 & \text { if } \psi^{*}+\Delta \theta \leq h, \\
\beta(1-\beta)\left(\Delta \theta+\psi^{*}-h\right) & \text { if } \psi^{*} \leq h<\psi^{*}+\Delta \theta .\end{cases}
\end{aligned}
$$

The difference in current profits $\pi_{1}^{D}(0,0)-\pi_{1}^{C}(0,0)$ depends, rather, on the current realisation of the firms' cost parameters. However, since the RHS of inequality (A-1) is increasing in $\pi_{1}^{D}(0,0)-\pi_{1}^{C}(0,0)$, the IC is verified to always hold when it holds for the largest value of this difference which, from Lemma A-1, is equal to $\psi^{*}$. Hence, using $\pi_{1}^{D}(0,0)-\pi_{1}^{C}(0,0)=\psi^{*},(\mathrm{~A}-2)$ and $(\mathrm{A}-3)$ in $(\mathrm{A}-1)$, a sufficient condition for (A-1) to hold is

$$
\delta \geq \begin{cases}\frac{\psi^{*}}{\psi^{*}+\beta(1-\beta) \Delta \theta} \equiv \delta_{a} & \text { if } \psi^{*}+\Delta \theta \leq h^{\circ} \\ \frac{\psi^{*}}{\psi^{*}+\beta(1-\beta)\left(h^{\circ}-\psi^{*}\right)} \equiv \delta_{b} & \text { if } \psi^{*} \leq h^{\circ}<\psi^{*}+\Delta \theta\end{cases}
$$

Notice that $\delta_{a}$ and $\delta_{b}$ in (A-4) differ only for the term in the denominator which multiplies $\beta(1-\beta)$. Also, $\delta_{a}$ is derived under the assumption that $\psi^{*}+\Delta \theta \leq h^{\circ}$, which implies $\Delta \theta \leq h^{\circ}-\psi^{*}$; on the other hand, $\delta_{b}$ is derived under the assumption that $h^{\circ}<\psi^{*}+\Delta \theta$, which implies $h^{\circ}-\psi^{*}<\Delta \theta$. Hence, we can write $\bar{\delta}(\psi(q)) \equiv \max \left\{\delta_{a}, \delta_{b}\right\}=\max \left\{\frac{\psi^{*}}{\psi^{*}+\beta(1-\beta) \Delta \theta}, \frac{\psi^{*}}{\psi^{*}+\beta(1-\beta)\left(h^{\circ}-\psi^{*}\right)}\right\}=\frac{\psi^{*}}{\psi^{*}+\beta(1-\beta) \min \left\{\Delta \theta, h^{\circ}-\psi^{*}\right\}}$.

To conclude the proof, it remains to look into Assumption 1. We now show that the conditions on $\delta$ which we showed to ensure that no deviation occurs from the cooperative strategies $s_{1}($.$) and s_{2}($.$) under$ Assumption 1 are also sufficient to ensure that, in the subgame of interest in Assumption 1, the firms' behaviour illustrated in the Assumption is indeed an equilibrium behaviour.

As an intermediate step, we focus on subgame $G(h, h)$, that is on the subgame which develops after both firms deviated in the past.

Lemma A-2. Consider the subgame $G(h, h)$. For any $h>0$, there exists an equilibrium in which both firms bid as in Lemma 1 with $q_{i}=q_{j}=0$ and, if awarded the project, provide quality equal to 0.

Proof. Trivial, by noting that both firms are handicapped because of their previous deviations, and do not have any incentive to provide quality and include its cost in their bids.

Lemma A-2 establishes that, after both firms deviated in the some past periods, the firms' equilibrium behaviour is with both firms behaving as in the static game. Next, we compare the critical discount factors in subgames $G(h, 0)$ and $G(0,0)$ when $h=h^{\circ}$.

Lemma A-3. Consider the subgame $G(0,0)$ and let $\delta(0,0)$ be the discount factor threshold which ensures the existence of an equilibrium in which both firms $i$ and $j$ behave as prescribed by their strategies $s_{i}($.$) and s_{j}($.$) . Consider also the subgame G\left(h^{\circ}, 0\right)$ and let $\delta\left(h^{\circ}, 0\right)$ be the discount factor threshold which ensures the existence of an equilibrium in which firm $i$ bids as in Lemma 1 with $q_{i}=0$ and, if awarded the project, provides quality equal to 0 , and firm $j$ behaves as prescribed by $s_{j}($.$) . Then,$ $\delta(0,0) \geq \delta\left(h^{\circ}, 0\right)$.

Proof. Consider period 1. In subgame $G\left(h^{\circ}, 0\right)$, firm 1 always behaves as described in Lemma A-1. Firm 2 behaves according to its strategy $s_{2}($.$) provided that its IC holds, which can be re-written as$

$$
\delta \geq \frac{\pi_{2}^{D}\left(h^{\circ}, 0\right)-\pi_{2}^{C}\left(h^{\circ}, 0\right)}{\left.\pi_{2}^{D}\left(h^{\circ}, 0\right)-\pi_{2}^{C}\left(h^{\circ}, 0\right)\right)+\left[E \pi_{2}^{C}\left(h^{\circ}, 0\right)-E \pi_{2}^{P}\left(h^{\circ}, h^{\circ}\right)\right]} \equiv \delta\left(h^{\circ}, 0\right) .
$$

Let $\delta(0,0)$ be the critical discount factor which ensures that firm 1's IC constraint in period 1 holds; in other words, let $\delta(0,0)$ be equal to the RHS of inequality (A-1).

Now, let $D \equiv \delta(0,0)-\delta\left(h^{\circ}, 0\right)$ where

$$
D=\frac{\Delta \pi_{1}(0,0)\left[E \pi_{2}^{C}\left(h^{\circ}, 0\right)-E \pi_{2}^{P}\left(h^{\circ}, h^{\circ}\right)\right]-\Delta \pi_{2}\left(h^{\circ}, 0\right)\left[E \pi_{1}^{C}(0,0)-E \pi_{1}^{P}\left(h^{\circ}, 0\right)\right]}{\left\{\Delta \pi_{2}\left(h^{\circ}, 0\right)+\left[E \pi_{2}^{C}\left(h^{\circ}, 0\right)-E \pi_{2}^{P}\left(h^{\circ}, h^{\circ}\right)\right]\right\}\left\{\Delta \pi_{1}(0,0)+\left[E \pi_{1}^{C}(0,0)-E \pi_{1}^{P}\left(h^{\circ}, 0\right)\right]\right\}} ;
$$


where $\Delta \pi_{1}(0,0) \equiv \pi_{1}^{D}(0,0)-\pi_{1}^{C}(0,0)$ and $\Delta \pi_{2}\left(h^{\circ}, 0\right) \equiv \pi_{2}^{D}\left(h^{\circ}, 0\right)-\pi_{2}^{C}\left(h^{\circ}, 0\right)$. Since the denominator of $D$ is always positive, then $D>0$ if and only if the numerator of $D$, which we will denote with $N$, is also positive. Rearranging $N$,

$$
N=N^{\prime} \Delta \pi_{1}(0,0)+N^{\prime \prime}\left[E \pi_{1}^{C}(0,0)-E \pi_{1}^{P}\left(h^{\circ}, 0\right)\right]
$$

where $N^{\prime} \equiv\left[E \pi_{2}^{C}\left(h^{\circ}, 0\right)-E \pi_{2}^{P}\left(h^{\circ}, h^{\circ}\right)\right]-\left[E \pi_{1}^{C}(0,0)-E \pi_{1}^{P}\left(h^{\circ}, 0\right)\right]$ and $N^{\prime \prime} \equiv \Delta \pi_{1}(0,0)-\Delta \pi_{2}\left(h^{\circ}, 0\right)$. Since all the other terms in $N$ are clearly positive, if $N^{\prime}$ and $N^{\prime \prime}$ are positive, then $N$ and $D$ are also positive.

From Lemma A-1, $N^{\prime \prime} \geq 0$. As to $N^{\prime}$, first note that, from standard results on Bertrand games, for any $h, E \pi_{2}^{P}(h, h)=E \pi_{1}^{C}(0,0)=\beta(1-\beta) \Delta \theta$ and

$$
E \pi_{2}^{C}(h, 0)= \begin{cases}h-\psi(q) & \text { if } \psi(q)+\Delta \theta \leq h, \\ (1-\beta(1-\beta))(h-\psi(q))+\beta(1-\beta) \Delta \theta & \text { if } \psi(q) \leq h<\psi(q)+\Delta \theta\end{cases}
$$

When $\psi(q)+\Delta \theta \leq h^{\circ}$, from (A-3) and (A-7), then $N^{\prime}=h^{\circ}-\psi(q)-2 \beta(1-\beta) \Delta \theta>0$. When $\psi(q) \leq h^{\circ}<\psi(q)+\Delta \theta$, from $(\mathrm{A}-3)$ and $(\mathrm{A}-7)$, then $N^{\prime}=h^{\circ}-\psi(q) \geq 0$.

Proof of Proposition 2. Assuming firm 2 sticks to its 'cooperative' strategy $s_{2}($.$) , the IC constraint for$ firm 1 can be written as follows:

$$
\pi_{1}^{C}(0,0)+\sum_{t=1}^{\infty} \delta^{t} E \pi_{1}^{C}(0,0) \geq \pi_{1}^{D}(0,0)+\delta \Pi_{1}^{P}\left(h^{\circ}, 0\right),
$$

where $\Pi_{1}^{P}\left(h^{\circ}, 0\right)$ is the present value of firm 1's future profits during and after the punishment triggered by its deviation, when no previous deviation has occurred and no further deviation occurs during the $T^{\circ}$ periods of punishment so that, after this phase, the 'cooperative' profits are re-established. Letting $\pi_{1}^{P}\left(h^{\circ}, 0\right)$ be the profits that firm 1 makes if, during the punishment phase, does not deviate from the punishment, we can define

$$
\Pi_{1}^{P}\left(h^{\circ}, 0\right) \equiv \sum_{t=0}^{T^{\circ}-1} \delta^{t} E \pi_{1}^{P}\left(h^{\circ}, 0\right)+\sum_{t=T}^{\infty} \delta^{t} E \pi_{1}^{C}(0,0) .
$$

Notice that, since we restrict our attention to $q_{B}^{P}=0$, we need not worry about a deviation by firm 1 during the punishment phase.

We need to check now the conditions under which firm 2 sticks to its cooperative strategy. In the game which unfolds after a deviation by firm 1, the IC constraint for firm 2 writes as

$$
\pi_{2}^{C}\left(h^{\circ}, 0\right)+\sum_{t=1}^{T^{\circ}-1} \delta^{t} E \pi_{2}^{C}\left(h^{\circ}, 0\right)+\sum_{t=T^{\circ}}^{\infty} \delta^{t} E \pi_{2}^{C}(0,0) \geq \pi_{2}^{D}\left(h^{\circ}, 0\right)+\delta \Pi_{2}^{\prime P}\left(h^{\circ}, h^{\circ}\right)
$$

where

$$
\Pi_{2}^{\prime P}\left(h^{\circ}, h^{\circ}\right) \equiv \sum_{t=0}^{T^{\circ}-2} \delta^{t} E \pi_{2}^{P}\left(h^{\circ}, h^{\circ}\right)+\delta^{T^{\circ}-1} E \pi_{2}^{P}\left(0, h^{\circ}\right)+\sum_{t=T^{\circ}}^{\infty} \delta^{t} E \pi_{2}^{C}(0,0) .
$$

In (A-10), the LHS is the discounted value of firm 2's profits when it sticks to its strategy $s_{2}($.$) . The first$ term is the value of the current profits, while the second is the discounted sum, over the next $T^{\circ}-1$ periods, of its 'cooperative' profits. The third term is the discounted value of firm 2's 'cooperative' profits once the handicap to its rival has been reset to 0 at the end of its punishment phase. The RHS is instead the discounted value of firm 2's profits when it deviates from its strategy $s_{2}($.$) . It features \Pi_{2}^{\prime P}$ which is defined in (A-11) and it is the the present value of firm 2's future profits during and after a phase of punishment for its deviation, when it does not deviate during the $T^{\circ}$ periods of punishment. In $\Pi_{2}^{\prime P}$, the first sum relates to the first $T^{\circ}-1$ periods of punishment of firm 2 , in which both firms are punished. The second 
term, instead, refers to the next $T^{\circ}$-th period, in which firm 2 is punished whereas firm 1's punishment has just ended; the last sum is the present value of the cooperative profits, when the punishment has ended for both firms. As in the discussion referring to firm 1 , since we restrict our attention to $q_{B}^{P}=0$, we need not worry about a deviation by firm 2 during the punishment phase.

When $\delta \rightarrow 1,(\mathrm{~A}-8)$ and $(\mathrm{A}-10)$ become

$$
T^{\circ} \geq \frac{\pi_{1}^{D}(0,0)-\pi_{1}^{C}(0,0)}{E \pi_{1}^{C}(0,0)-E \pi_{1}^{P}\left(h^{\circ}, 0\right)}
$$

and

$$
T^{\circ} \geq 1+\frac{\pi_{2}^{D}\left(h^{\circ}, 0\right)-\pi_{2}^{C}\left(h^{\circ}, 0\right)+E \pi_{2}^{P}\left(0, h^{\circ}\right)-E \pi_{2}^{C}(0,0)}{E \pi_{2}^{C}\left(h^{\circ}, 0\right)-E \pi_{2}^{P}\left(h^{\circ}, h^{\circ}\right)}
$$

which, when holding together, ensure that both firms do not have an incentive to deviate from their cooperative strategies.

The RHS of (A-12) is increasing in the difference in current profits, $\pi_{1}^{D}(0,0)-\pi_{1}^{C}(0,0)$, which depends on the current realisation of the firms' cost parameters. Hence, (A-12) is verified to always hold when it holds for the largest value of this difference, which by Lemma A-1, is $\psi^{*}$. Therefore, using $\pi_{1}^{D}(0,0)-\pi_{1}^{C}(0,0)=\psi^{*}$, (A-12) is a sufficient condition for the IC of firm 1 to hold. An identical argument can be used for inequality (A-13). On the other hand, for inequalities (A-12) and (A-13), the expected profits expressions do not depend on the current realisation of the firms' cost parameters, but depend on the level of the handicap. Hence, we need to check which conditions ensure they hold, for the different values of the handicap.

Case 1: $\Delta \theta+\psi^{*} \leq h^{\circ}$. For firm 1, using (A-2) and (A-3), inequality (A-12) becomes $T^{\circ} \geq T_{1}^{a} \equiv \frac{\psi^{*}}{\beta(1-\beta) \Delta \theta}$. For firm 2, by applying symmetry in (A-2) and (A-3), for any $h, E \pi_{2}^{C}(0,0)=E \pi_{2}^{C}(h, h)=E \pi_{1}^{C}(0,0)$ and $E \pi_{2}^{P}(0, h)=E \pi_{1}^{P}(h, 0)$. Using these and (A-7), inequality (A-13) becomes $T^{\circ} \geq T_{2}^{a} \equiv 1+\frac{\psi^{*}-\beta(1-\beta) \Delta \theta}{h^{\circ}-\psi^{*}-\beta(1-\beta) \Delta \theta}$.

When $\psi^{*} \geq \beta(1-\beta) \Delta \theta$, since $T_{1}^{a} \geq T_{2}^{a}$, neither firm has an incentive to deviate when $T^{\circ} \geq T_{1}^{a} \geq 1$. When, instead, $\psi^{*}<\beta(1-\beta) \Delta \theta$, since $T_{1}^{a}<T_{2}^{a}$, neither firm has an incentive to deviate when $T^{\circ} \geq T_{2}^{a}$; however, $T_{2}^{a}<1$, which is the shortest admissible punishment length.

Case 2: $\psi^{*} \leq h^{\circ}<\Delta \theta+\psi^{*}$ : for firm 1, using (A-2) and (A-3), inequality (A-12) becomes $T^{\circ} \geq T_{1}^{b} \equiv$ $\frac{\psi^{*}}{\beta(1-\beta)\left(h^{\circ}-\psi^{*}\right)}$. For firm 2, by applying symmetry in (A-2) and (A-3), for any $h, E \pi_{2}^{C}(0,0)=E \pi_{2}^{C}(h, h)=$ $E \pi_{1}^{C}(0,0)$ and $E \pi_{2}^{P}(0, h)=E \pi_{1}^{P}(h, 0)$. Using these and (A-7), inequality (A-13) becomes $T^{\circ} \geq T_{2}^{b} \equiv$ $1+\frac{\psi^{*}-\beta(1-\beta)\left(h^{\circ}-\psi^{*}\right)}{(1-\beta(1-\beta))\left(h^{\circ}-\psi^{*}\right)}$.

When $\psi^{*} \geq \beta(1-\beta) \Delta \theta$, since $\frac{\partial\left(T_{1}^{b}-T_{2}^{b}\right)}{\partial h^{\circ}}<0$ and $\lim _{h^{\circ} \rightarrow\left(\psi^{*}+\Delta \theta\right)^{-}}\left(T_{1}^{b}-T_{2}^{b}\right)>0$, then $T_{1}^{b} \geq T_{2}^{b}$, and neither firm has an incentive to deviate when $T^{\circ} \geq T_{1}^{b} \geq 1$. If, instead, $\psi^{*}<\beta(1-\beta) \Delta \theta$ we have to consider two subcases: $a$ ) if $h^{\circ} \leq \frac{(1-\beta(1-\beta)) \psi^{*}}{\beta(1-\beta)}$, since $T_{1}^{b} \geq T_{2}^{b}$, neither firm has an incentive to deviate when $\left.T^{\circ} \geq T_{1}^{b} \geq 1 ; b\right)$ if $h^{\circ}>\frac{(1-\beta(1-\beta)) \psi^{*}}{\beta(1-\beta)}$, since $T_{1}^{b}<T_{2}^{b}$, neither firm has an incentive to deviate when $T^{\circ} \geq T_{2}^{b}$; however, $T_{2}^{b}<1$, which is the shortest admissible punishment length.

Case 3: $\psi^{*}=h^{\circ}$. Inequalities (A-12) and (A-13) become $T^{\circ} \geq \infty$. 


\section{Appendix B (for the use of referees only)}

In this Appendix, we provide some additional material and results, not to be published and for the use of referees only.

\section{B-1 Static procurement game}

We provide here full details of the relevant static procurement game which are instrumental to derive the firms' payoffs in (A-2), (A-3) and (A-7). The proofs of the following Lemmata are a simple application of standard results on (possibly) asymmetric Bertrand games, and are omitted.

Lemma B-1. Assume $h_{1}=h_{2}=h \geq 0$; assume also that firms 1 and 2 both bid anticipating to deliver quality $q_{1}$ and $q_{2}$, respectively, with $q_{1}=q_{2}=q \geq 0$. Then

i) when $L H$ (or $H L$, after inverting the identity of the firms), optimal bids and scores are $b_{1}=$ $b_{2}=\theta_{H}+\psi(q)$, so that scores are $S_{1}=S_{2}=\theta_{H}+\psi(q)+h$. Firm 1 wins and players' payoffs are

$$
\pi_{1}=\Delta \theta ; \quad \quad \quad \pi_{2}=0 ; \quad u=v+q-\theta_{H}-\psi(q)
$$

iii) when $L L$ (or $H H$, after substituting the subscript $L$ with $H$ ), optimal bids and scores are $b_{1}=b_{2}=\theta_{L}+\psi(q)$, so that scores are $S_{1}=S_{2}=\theta_{L}+\psi(q)+h$. The two firms tie and the project is awarded randomly. The players' (expected, in case of the buyer) payoffs are

$$
\pi_{1}=0 ; \quad \pi_{2}=0 ; \quad E u=v+q-\theta_{L}-\psi(q) .
$$

Lemma B-2. Assume $h_{1}=h>0$ and $h_{2}=0$; assume also that firm 1 bids anticipating to deliver quality $q_{1}=0$ and firm 2 bids anticipating to deliver quality $q_{2}>0$. Then

i) when $L H$ and

i.i) $h<\Delta \theta+\psi(q)$, optimal bids are $b_{1}=\theta_{H}+\psi(q)-h$ and $b_{2}=\theta_{H}+\psi(q)$, so that scores are $S_{1}=\theta_{H}+\psi(q)$ and $S_{2}=\theta_{H}+\psi(q)$. Firm 1 wins and players' payoffs are

$$
\pi_{1}=\Delta \theta+\psi(q)-h ; \quad \pi_{2}=0 ; \quad u=v-\theta_{H}-\psi(q)+h ;
$$

i.ii) $h=\Delta \theta+\psi(q)$, optimal bids are $b_{1}=\theta_{L}$ and $b_{2}=\theta_{H}+\psi(q)$, so that scores are $S_{1}=\theta_{H}+\psi(q)$ and $S_{2}=\theta_{H}+\psi(q)$. The two firms tie and the project is awarded randomly. The players' (expected, in case of the buyer) payoffs are

$$
\pi_{1}=0 ; \quad \pi_{2}=0 ; \quad E u=v-\theta_{L}+\frac{1}{2}(q-h)
$$


i.iii) $\Delta \theta+\psi(q)<h$, optimal bids are $b_{1}=\theta_{L}$ and $b_{2}=\theta_{L}+h$, so that scores are $S_{1}=\theta_{L}+h$ and $S_{2}=\theta_{L}+h$. Firm 2 wins and players' payoffs are

$$
\pi_{1}=0 ; \quad \pi_{2}=h-\Delta \theta-\psi(q) ; \quad u=v+q-\theta_{L}-h ;
$$

ii) when $H L$ and

i.i) $h<\psi(q)-\Delta \theta$, optimal bids are $b_{1}=\theta_{L}+\psi(q)-h$ and $b_{2}=\theta_{L}+\psi(q)$, so that scores are $S_{1}=\theta_{L}+\psi(q)$ and $S_{2}=\theta_{L}+\psi(q)$. Firm 1 wins and players' payoffs are

$$
\pi_{1}=\psi(q)-\Delta \theta-h ; \quad \pi_{2}=0 ; \quad u=v-\theta_{L}-\psi(q)+h
$$

i.ii) $h=\psi(q)-\Delta \theta$, optimal bids are $b_{1}=\theta_{H}$ and $b_{2}=\theta_{L}+\psi(q)$, so that scores are $S_{1}=\theta_{H}+h$ and $S_{2}=\theta_{L}+\psi(q)$. The two firms tie and the project is awarded randomly. The players' (expected, in case of the buyer) payoffs are

$$
\pi_{1}=0 ; \quad \pi_{2}=0 ; \quad E u=v+\frac{1}{2}(q-h) ;
$$

i.iii) $\psi(q)-\Delta \theta<h$, optimal bids are $b_{1}=\theta_{H}$ and $b_{2}=\theta_{H}+h$, so that $S_{1}=\theta_{H}+h$ and $S_{2}=\theta_{H}+h$. Firm 2 wins and players' payoffs are

$$
\pi_{1}=0 ; \quad \pi_{2}=h+\Delta \theta-\psi(q) ; \quad u=v+q-\theta_{H}-h ;
$$

iii) when $L L$ (or $H H$, after substituting the subscript $L$ with $H$ ) and

iii.i) $h<\psi(q)$, optimal bids are $b_{1}=\theta_{L}+\psi(q)-h$ and $b_{2}=\theta_{L}+\psi(q)$, so that scores are $S_{1}=\theta_{L}+\psi(q)$ and $S_{2}=\theta_{L}+\psi(q)$. Firm 1 wins and players' payoffs are

$$
\pi_{1}=\psi(q)-h ; \quad \quad \pi_{2}=0 ; \quad u=v-\theta_{L}-\psi(q)+h ;
$$

iii.ii) $h=\psi(q)$, optimal bids are $b_{1}=\theta_{L}$ and $b_{2}=\theta_{L}+\psi(q)$, so that scores are $S_{1}=\theta_{L}+h$ and $S_{2}=\theta_{L}+\psi(q)$. The two firms tie and the project is awarded randomly. The players' (expected, in case of the buyer) payoffs are

$$
\pi_{1}=0 ; \quad \pi_{2}=0 ; \quad E u=v-\theta_{L}+\frac{1}{2}(q-h) ;
$$

iii.iii) $\psi(q)<h$, optimal bids are $b_{1}=\theta_{L}$ and $b_{2}=\theta_{L}+h$, so that scores are $S_{1}=\theta_{L}+h$ and $S_{2}=\theta_{L}+h$. Firm $j$ wins and players' payoffs are

$$
\pi_{1}=0 ; \quad \pi_{2}=h-\psi(q) ; \quad u=v+q-\theta_{L}-h .
$$




\section{B-2 Equilibrium with stick and carrot strategies and $T=1$ or} $T=2$

This Section provides the full results summarised in footnote 32 regarding the existence, under some parametric conditions, of an explicit discount factor strictly lower than 1 for low values of $T^{\circ}$, the length of the punishment for a deviating firm.

Proposition B-1. Assume the buyer is committed to her strategy. When $T^{\circ}=1$ or $T^{\circ}=2$, provided that $h \geq \psi\left(q^{*}\right)$ and some parametric conditions hold, the strategy profile $s_{B}\left(h^{\circ}, q^{*}, 0, T^{\circ}\right)$ and $s_{i}\left(q^{*}\right)$ (with $i=1,2$ ) defines a self-enforcing RPC whenever the players' discount factor is higher than a critical value strictly lower than 1.

In particular, the strategy profile $s_{B}\left(h^{\circ}, q^{*}, 0, T^{\circ}\right)$ and $s_{i}\left(q^{*}\right)$ (with $i=1,2$ ) defines a selfenforcing $R P C$

- when $T^{\circ}=1$ and

$$
\delta \geq \begin{cases}\frac{\psi\left(q^{*}\right)}{\mathcal{B} \Delta \theta} & \text { if } \psi\left(q^{*}\right) \in\left(0, \min \left\{\mathcal{B} \Delta \theta, h^{\circ}-\Delta \theta\right\}\right] \\ \frac{\psi\left(q^{*}\right)}{\mathcal{B}\left(h^{\circ}-\psi\left(q^{*}\right)\right)} & \text { if } \psi\left(q^{*}\right) \in\left(\max \left\{0, h^{\circ}-\Delta \theta\right\}, h^{\circ} \frac{\mathcal{B}}{1+\mathcal{B}}\right] .\end{cases}
$$

- when $T^{\circ}=2$ and

$$
\delta \geq \begin{cases}\frac{\sqrt{[\mathcal{B} \Delta \theta]^{2}+4 \mathcal{B} \psi\left(q^{*}\right) \Delta \theta}-\mathcal{B} \Delta \theta}{\mathcal{B} \Delta \theta} & \text { if } \psi\left(q^{*}\right) \in\left(0, \min \left\{\Delta \theta, h^{\circ}-\Delta \theta\right\}\right], \\ \frac{\sqrt{\left[\mathcal{B}\left(h^{\circ}-\psi\left(q^{*}\right)\right)\right]^{2}+4 \mathcal{B} \psi\left(q^{*}\right)\left(h^{\circ}-\psi\right)}-\mathcal{B}\left(h^{\circ}-\psi\left(q^{*}\right)\right)}{\mathcal{B}\left(h^{\circ}-\psi\left(q^{*}\right)\right)} & \text { if } \psi\left(q^{*}\right) \in\left(\max \left\{0, h^{\circ}-\Delta \theta\right\}, \Delta \theta\right] .\end{cases}
$$

where $\mathcal{B} \equiv \beta(1-\beta)$

Proof. Take the case $T^{\circ}=1$. Substituting $T^{\circ}=1$ in (A-8) and rearranging gives

$$
\pi_{1}^{C}(0,0)+\delta E \pi_{1}^{C}(0,0) \geq \pi_{1}^{D}(0,0)+\delta E \pi_{1}^{P}\left(h^{\circ}, 0\right)
$$

solving it w.r.to $\delta$ gives

$$
\delta \geq \frac{\pi_{1}^{D}(0,0)-\pi_{1}^{C}(0,0)}{E \pi_{1}^{C}(0,0)-E \pi_{1}^{P}\left(h^{\circ}, 0\right)} .
$$

Similarly, substituting $T^{\circ}=1$ in (A-10) and rearranging gives

$$
\pi_{2}^{C}\left(h^{\circ}, 0\right)+\delta E \pi_{2}^{C}(0,0) \geq \pi_{2}^{D}\left(h^{\circ}, 0\right)+\delta E \pi_{2}^{P}\left(0, h^{\circ}\right)
$$

solving it w.r.to $\delta$ gives

$$
\delta \geq \frac{\pi_{2}^{D}\left(h^{\circ}, 0\right)-\pi_{2}^{C}\left(h^{\circ}, 0\right)}{E \pi_{2}^{C}(0,0)-E \pi_{2}^{P}\left(0, h^{\circ}\right)} .
$$

Following Lemma A-1 and equations (A-2), (A-3) and (A-7), when $\psi^{*}+\Delta \theta \leq h^{\circ}$, inequality (B-15) becomes $\delta \geq \frac{\psi^{*}}{\mathcal{B} \Delta \theta} \equiv \delta_{\alpha}$; when instead $\psi^{*} \leq h^{\circ}<\psi^{*}+\Delta \theta$, inequality (B-15) becomes 
$\delta \geq \frac{\psi^{*}}{\mathcal{B}\left(h^{\circ}-\psi^{*}\right)} \equiv \delta_{\beta}$. On the other hand, when $\psi^{*}+\Delta \theta \leq h^{\circ}$, inequality (B-17) becomes $\delta \geq \delta_{\alpha}$; when instead $\psi^{*} \leq h^{\circ}<\psi^{*}+\Delta \theta$, inequality (B-17) becomes $\delta \geq \frac{h^{\circ}-\Delta \theta}{\mathcal{B}\left(h^{\circ}-\psi^{*}\right)} \equiv \delta_{\gamma}$.

To establish the result, first notice that $\delta_{\gamma}<\delta_{\beta}$. Hence, both (B-15) and (B-17) hold if $\delta \geq \delta_{\alpha}$ when $\psi^{*}+\Delta \theta \leq h^{\circ}$, and if $\delta \geq \delta_{\beta}$ when $\psi^{*} \leq h^{\circ}<\psi^{*}+\Delta \theta$. Notice also that $\delta_{\alpha}<1$ when $\psi^{*}<\mathcal{B} \Delta \theta$, while $\delta_{\beta}<1$ when $\psi^{*}<h^{\circ} \frac{\mathcal{B}}{1+\mathcal{B}}$.

Take now the case $T^{\circ}=2$. Substituting $T^{\circ}=2$ in (A-8) and rearranging gives

$$
\pi_{1}^{C}(0,0)+\delta E \pi_{1}^{C}(0,0)+\delta^{2} E \pi_{1}^{C}(0,0)-\left[\pi_{1}^{D}(0,0)+\delta E \pi_{1}^{P}\left(h^{\circ}, 0\right)+\delta^{2} E \pi_{1}^{P}\left(h^{\circ}, 0\right)\right] \geq 0
$$

which is a convex 2 nd degree inequality in $\delta$. The LHS is equal 0 when

$$
\delta_{1}, \delta_{2}=\frac{ \pm \sqrt{E_{1}^{2}+4 E_{1}\left[\pi_{1}^{D}(0,0)-\pi_{1}^{C}(0,0)\right]}-E_{1}}{2 E_{1}},
$$

where $E_{1} \equiv E \pi_{1}^{C}(0,0)-E \pi_{1}^{P}\left(h^{\circ}, 0\right)$. Since, by construction, $E_{1}>0$ and $\pi_{1}^{D}(0,0)>\pi_{1}^{C}(0,0)$, only one expression in (B-19) is positive and we can conclude that (A-8) is satisfied when

$$
\delta \geq \frac{\sqrt{E_{1}^{2}+4 E_{1}\left[\pi_{1}^{D}(0,0)-\pi_{1}^{C}(0,0)\right]}-E_{1}}{2 E_{1}} .
$$

Substituting $T^{\circ}=2$ in (A-10) and rearranging gives

$$
\pi_{2}^{C}\left(h^{\circ}, 0\right)+\delta E \pi_{2}^{C}\left(h^{\circ}, 0\right)+\delta^{2} E \pi_{2}^{C}(0,0)-\left[\pi_{2}^{D}\left(h^{\circ}, 0\right)+\delta E \pi_{2}^{P}\left(h^{\circ}, h^{\circ}\right)+\delta^{2} E \pi_{2}^{P}\left(0, h^{\circ}\right)\right] \geq 0
$$

which is a convex second-degree inequality in $\delta$. The LHS is equal 0 when

$$
\delta_{1}, \delta_{2}=\frac{ \pm \sqrt{E_{2}^{2}+4 R_{2}\left[\pi_{2}^{D}\left(h^{\circ}, 0\right)-\pi_{2}^{C}\left(h^{\circ}, 0\right)\right]}-E_{2}}{2 R_{2}} .
$$

where $E_{2} \equiv E \pi_{2}^{C}\left(h^{\circ}, 0\right)-E \pi_{2}^{P}\left(h^{\circ}, h^{\circ}\right), R_{2} \equiv E \pi_{2}^{P}\left(0, h^{\circ}\right)-E \pi_{2}^{C}(0,0)$. Since, by construction, $E_{2}>0, R_{2}<0$ and $\pi_{2}^{D}\left(h^{\circ}, 0\right)>\pi_{2}^{C}\left(h^{\circ}, 0\right)$, only one value in (B-22) is positive and we can conclude that $(\mathrm{A}-10)$ is satisfied when

$$
\delta \geq \frac{-\sqrt{E_{2}^{2}+4 R_{2}\left[\pi_{2}^{D}\left(h^{\circ}, 0\right)-\pi_{2}^{C}\left(h^{\circ}, 0\right)\right]}-E_{2}}{2 R_{2}} .
$$

Following Lemma A-1 and equations (A-2), (A-3) and (A-7), inequality (B-20) becomes $\delta \geq$ $\frac{1}{2 \mathcal{B} \Delta \theta}\left[\sqrt{(\mathcal{B} \Delta \theta)^{2}+4 \mathcal{B} \psi^{*} \Delta \theta}-\mathcal{B} \Delta \theta\right] \equiv \delta_{\mu} ;$ when instead $\psi^{*} \leq h^{\circ}<\psi^{*}+\Delta \theta$, then inequality (B-20) becomes $\delta \geq \frac{1}{2 \mathcal{B}\left(h^{\circ}-\psi^{*}\right)}\left[\sqrt{\left(\mathcal{B}\left(h^{\circ}-\psi^{*}\right)\right)^{2}+4 \mathcal{B} \psi\left(h^{\circ}-\psi^{*}\right)}-\mathcal{B}\left(h^{\circ}-\psi^{*}\right)\right] \equiv \delta_{\rho}$. On the other hand, when $\psi^{*}+\Delta \theta \leq h^{\circ}$, then inequality (B-23) becomes $\delta \geq \frac{1}{2 \mathcal{B} \Delta \theta}\left[\sqrt{\left(h^{\circ}-\psi^{*}-\mathcal{B} \Delta \theta\right)^{2}+4 \mathcal{B} \psi^{*} \Delta \theta}-\right.$ $\left.\left(h^{\circ}-\psi^{*}-\mathcal{B} \Delta \theta\right)\right] \equiv \delta_{\nu}$; when instead $\psi^{*} \leq h^{\circ}<\psi^{*}+\Delta \theta$, then inequality (B-23) becomes $\delta \geq \frac{1}{2 \mathcal{B}\left(h^{\circ}-\psi^{*}\right)}\left[\sqrt{\left((1-\mathcal{B})\left(h^{\circ}-\psi^{*}\right)\right)^{2}+4 \mathcal{B}\left(h^{\circ}-\Delta \theta\right)\left(h^{\circ}-\psi^{*}\right)}-(1-\mathcal{B})\left(h^{\circ}-\psi^{*}\right)\right] \equiv \delta_{\sigma}$. 
To establish the result, first notice that $\delta_{\mu}>\delta_{\nu}$, and $\delta_{\rho}>\delta_{\sigma}$. Hence, both (B-20) and (B-23) hold if $\delta \geq \delta_{\mu}$ when $\psi^{*}+\Delta \theta \leq h$ and $\delta \geq \delta_{\rho}$ when $\psi^{*} \leq h^{\circ}<\psi^{*}+\Delta \theta$. Also, $\delta_{\mu}, \delta_{\rho}<1$.

\section{B-3 A cooperative equilibrium under asymmetric information: The case of debarment}

In this section, we remove the assumption of symmetric information between firms on (fixed) production costs and consider the case of privately informed firms. More precisely, each firm $i=1,2$ in each period $t=0, \ldots, \infty$ learns its own fixed cost, but only knows that firm $j$ 's cost, $j=3-i$, is equal to $\theta_{L}\left(\theta_{H}\right.$, respectively) with probability $\beta$ ( $1-\beta$, respectively). In what follows we prove that a pair of RPCs enforcing quality $q^{*}$ still exists when the buyer can commit to a very high level of handicap which is equivalent to a de facto debarment of the cheating firm(s) from the procurement market. More precisely, we show the existence of such RPCs for all levels of handicap $h \geq \bar{h}$, where $\bar{h} \equiv \psi\left(q^{*}\right)+\Delta \theta$.

We extend the trigger strategies of Section 4.3.1 to the case of asymmetric information by introducing strategies $s_{B}\left(h, q^{*}\right), s_{i, L}\left(q^{*}\right)$ and $s_{i, H}\left(q^{*}\right)$ that are similar to $s_{B}\left(h^{C}, q^{*}\right)$ and $s_{i}\left(q^{*}\right)$ except for the restriction on the level of handicap and for the firm's strategy being type-dependent. Define $\psi\left(q^{*}\right) \equiv \psi^{*}$.

Proposition B-2. Assume that the buyer commits to $h^{\circ} \geq \bar{h}$. Let $\bar{\beta} \equiv \frac{\Delta \theta}{h-\psi^{*}}$ and

$$
\delta^{a s y} \equiv \frac{\psi^{*}}{\psi^{*}+\beta(1-\beta) \Delta \theta} .
$$

Then, if $\beta \geq \bar{\beta}$ and $\psi^{*}>\Delta \theta$, and provided that $\delta \geq \delta^{a s y}$, the strategies profile $s_{B}\left(h^{\circ}, q^{*}\right), s_{i, L}\left(q^{*}\right)$ and $s_{i, H}\left(q^{*}\right), i=1,2$, defines a self-enforcing $R P C$ whereby the project is awarded in each period to the most efficient firm, which delivers quality $q^{*}$.

Proof. Take any time $t \geq 0$. For both types of firm $i$ 's $(i=1,2)$ the incentive compatibility (IC) constraint simply writes

$$
\pi_{i}^{C}+\frac{\delta}{1-\delta} E \pi_{i}^{C} \geq \pi_{i}^{D}+\frac{\delta}{1-\delta} E \pi_{i}^{P}
$$

where, provided that the other players follow their grim trigger strategies, $\pi_{i}^{C}$ ( $\pi_{i}^{D}$, respectively) are the profits that firm $i$ makes in period $t$ when sticking to (deviating from) its strategy $s_{i}\left(q^{*}\right) ; E \pi_{i}^{C}$ $\left(E \pi_{i}^{P}\right.$, respectively) are the expected single-period profits that it makes from period $t+1$ onwards when sticking to (being punished after a deviation from) strategy $s_{i}\left(q^{*}\right)$. This IC constraint can be re-written as

$$
\delta \geq \frac{\pi_{i}^{D}-\pi_{i}^{C}}{\left(\pi_{i}^{D}-\pi_{i}^{C}\right)+\left(E \pi_{i}^{C}-E \pi_{i}^{P}\right)} .
$$

The string of lemmata below will pin down the values of the relevant expressions in B-24. 
Lemma B-3. In the constituent game, if both types of either firm bid to deliver quality $q^{*}$ then type $\theta_{H}$ 's equilibrium payoff is zero whereas type $\theta_{L}$ 's equilibrium payoff is $(1-\beta) \Delta \theta$.

Proof. Since both types bid by taking into account that they will deliver quality $q^{*}$, bidder $i$ 's 'anticipated' production costs will be $c_{i}\left(\theta_{L}, 0, \psi^{*}\right)=\theta_{L}+\psi^{*}$ when its type is $\theta_{L}$ and $c_{i}\left(\theta_{H}, 0, \psi^{*}\right)=\theta_{H}+\psi^{*}$ when its type is $\theta_{H}$, with $i=1,2$. Given that the type space is discrete, we can immediately apply Maskin and Riley (1985) to derive the equilibrium strategies and payoffs. That is, type $\theta_{H}$ of either firm will bid $\theta_{H}+\psi^{*}$ with probability 1 , whereas type $\theta_{L}$ will randomize according to the distribution function $F(\cdot)$ defined over the support $[\underline{b}, \bar{b}]=\left[\theta_{L}+\psi^{*}+(1-\beta) \Delta \theta, \theta_{H}+\psi^{*}\right]$. More precisely, the probability that type $\theta_{L}$ will bid at most with $b_{L}, F\left(b_{L}\right)$, has to satisfy the following indifference condition

$$
\left(b_{L}-\theta_{L}-\psi^{*}\right)\left[(1-\beta)+\beta\left(1-F\left(b_{L}\right)\right)\right]=(1-\beta) \Delta \theta,
$$

where the value of type $\theta_{L}$ 's expected payoff, $(1-\beta) \Delta \theta$, is derived by imposing the boundary condition $F\left(\theta_{H}+\psi^{*}\right)=1$. Then

$$
F\left(b_{L}\right)=\frac{\left(b_{L}-\theta_{L}-\psi^{*}\right)-(1-\beta) \Delta \theta}{\beta\left(b_{L}-\theta_{L}-\psi^{*}\right)} .
$$

It is immediate to verify that the equilibrium distribution function is monotonically increasing over the relevant support and that either type has no incentive to deviate from the equilibrium bidding strategy.

Lemma B-4. Take any constituent game after bidder $j$ gets handicapped. Suppose that bidder $i$ keeps adhering to its strategy $s_{i}\left(q^{*}\right)$. If

$$
\beta \geq \bar{\beta} \equiv \frac{\Delta \theta}{h^{\circ}-\psi^{*}},
$$

there exists a pure strategy Nash equilibrium where type $\theta_{L}$ and $\theta_{H}$ of bidder $j$ bid $\theta_{L}$ and $\theta_{H}$ respectively; and both types of bidder $i=3-j$ bid $\theta_{L}+h^{\circ}$. At equilibrium, bidder $i$ is selected and delivers quality $q^{*}$.

Proof. Suppose bidder $j$ 's type bid according to the stated strategies and consider type $\theta_{L}$ of bidder $i$. A bid equal to $\theta_{L}+h^{\circ}$ yields a profit of $h^{\circ}-\psi^{*}$. Raising the bid to $\theta_{H}+h^{\circ}$ yields $(1-\beta)\left(\Delta \theta+h^{\circ}-\psi^{*}\right)$ since type $\theta_{L}$ of bidder $i$ would only defeat the high type of bidder $j$. Then

$$
h^{\circ}-\psi^{*} \geq(1-\beta)\left(\Delta \theta+h^{\circ}-\psi^{*}\right) \Leftrightarrow \frac{\beta}{1-\beta} \geq \frac{\Delta \theta}{h^{\circ}-\psi^{*}},
$$

which is fulfilled given the assumption on $\beta$. Consider now type $\theta_{H}$ of bidder $i$. A bid equal to $\theta_{L}+h^{\circ}$ yields an expected profit of $h^{\circ}-\psi^{*}-\Delta \theta$. A bid of $\theta_{H}+h^{\circ}$ yields $(1-\beta)\left(h-\psi^{*}\right)$ 
as it only defeats type $\theta_{H}$ of bidder $j$. Then

$$
h^{\circ}-\psi^{*}-\Delta \theta \geq(1-\beta)\left(h^{\circ}-\psi^{*}\right) \Leftrightarrow \beta \geq \frac{\Delta \theta}{h^{\circ}-\psi^{*}},
$$

which is again fulfilled given the assumption on $\beta$. Given bidder $i$ 's strategy profile, bidder $j$ does not have any incentive to deviate.

Lemma B-3 and B-4 allow us to derive the value of $E \pi_{i}^{C}$ and $E \pi_{i}^{P}$ in B-24, which are equal to $\beta(1-\beta) \Delta \theta$ and 0 , respectively. We are now left with finding the highest possible value of $\pi_{i}^{D}-\pi_{i}^{C}$ that will determine the critical threshold of the discount factor for the strategies $s_{B}\left(h^{C}, q^{*}\right)$ and $s_{i}\left(q^{*}\right)$ to be part of an equilibrium at any $t \geq 0$. Generally, this difference will be type-dependent, thus only the higher value will matter for the critical threshold. The lemma below provides the last step of the proof.

Lemma B-5. Let $\psi^{*}>\Delta \theta$, and suppose that at any $t \geq 0$ firm $j=1,2$ bids according to its cooperative strategy $s_{j}\left(q^{*}\right)$. Then firm $i$ 's $(i \neq j)$ highest (static) net gain from deviating from $s_{i}\left(q^{*}\right)$ is equal to $\psi^{*}$.

Proof. Consider first type $\theta_{H}$ of bidder $i$. Given the strategies adopted by player $j$ 's types, type $\theta_{H}$ of bidder $i$ has two relevant deviations, namely to bid either (slightly below) $\theta_{H}+\psi^{*}$ or $\theta_{L}+\psi^{*}+(1-\beta) \Delta \theta$. The first option yields an expected payoff of $(1-\beta) \psi^{*}$, whereas the second yields $\psi^{*}-\beta \Delta \theta>(1-\beta) \psi^{*}$ given the assumption on $\psi^{*}$. It is also immediate that any bid in the interval $(\underline{b}, \bar{b})=\left(\theta_{L}+\psi^{*}+(1-\beta) \Delta \theta, \theta_{H}+\psi^{*}\right)$ will yield an expected payoff strictly lower than $\psi^{*}-\beta \Delta \theta$, which also represents type $\theta_{H}$ 's highest net gain from deviating from the cooperative strategy. Consider now type $\theta_{L}$ of firm $i$. The most profitable is simply to bid (slightly below) $\theta_{L}+\psi^{*}+(1-\beta) \Delta \theta$ with probability 1 and not deliver quality. This strategy yields a (static) net gain from deviation equal to $\psi^{*}$.

Lemma B-5 shows that at each $t \geq 0$ it is type $\theta_{L}$ of firm $i$ which has the highest net gain from deviating from the cooperative strategy, implying that the relevant value of the difference $\pi_{i}^{D}-\pi_{i}^{C}$ is equal to $\psi^{*}$. Consequently, at time $t=0$ an RPC is sustained by the strategies $s_{B}\left(h, q^{*}\right), s_{i, L}\left(q^{*}\right)$ and $s_{i, H}\left(q^{*}\right)$ if and only if $\delta \geq \delta^{a s y}$.

For low and intermediate values of $h$ the characterisation of the stage-game equilibrium bids becomes more convoluted. Indeed, for sufficiently low values of $h$ the following chain of inequalities may hold:

$$
c_{i}\left(\theta_{L}, 0, q^{*}\right)<c_{j}\left(\theta_{L}, h, q^{*}\right)<c_{i}\left(\theta_{H}, 0, q^{*}\right)<c_{j}\left(\theta_{H}, h, q^{*}\right), i=1,2 ; j=3-i .
$$

To our knowledge, Doni and Menicucci (2013) are the first ones to characterize Bayes-Nash equilibria for first- and second-price (selling) two-player auction with discrete valuations even when 
the latter 'overlap' as in the case depicted by the above inequalities. ${ }^{35}$ This paper also shows that the mixed strategy equilibria involve players using different cumulative distribution functions depending on the absolute difference between players' valuations. In other terms, the equilibrium distribution functions depend upon the differences between the terms above. Thus extending our model to encompass fully asymmetric information between firms would result in complicating quite considerably the equilibrium characterization of the stage game (but only once a deviation from cooperation is observed).

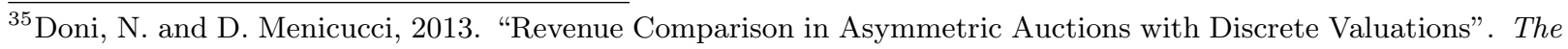
B.E. Journal of Theoretical Economics 13(1). 